\title{
Space Food and Nutrition in a Long Term Manned Mission
}

\author{
Funmilola Adebisi Oluwafemi ${ }^{1}$ (D) Andrea De La Torre ${ }^{2}$. Esther Morayo Afolayan ${ }^{3}$. \\ Bolanle Magret Olalekan-Ajayi ${ }^{4}$ Bal Dhital ${ }^{5}$. Jose G. Mora-Almanza ${ }^{6}$. George Potrivitu ${ }^{4}$. Jessica Creech $^{4}$. \\ Aureliano Rivolta ${ }^{7}$
}

Received: 17 June 2018 / Revised: 30 June 2018 / Accepted: 20 July 2018 / Published online: 25 August 2018

(c) The Author(s) 2018

\begin{abstract}
Fulfillment of space exploration mission is key, but much more important are the lives of the explorers. Keeping the astronauts alive, jolly and healthy for long term manned mission has recently being a major and important research area. A major contribution seems to be the food they eat. For short term space manned missions, astronauts food could be taken along with them from Earth, but for manned missions to the Moon, Mars and Venus which are the current research destinations for long term space missions, they must find a means for their nutrition such as growing plants and finding any other alternatives for their survival. As most of these proposed missions have being designed to be one-way missions whereby the astronauts will not come back to the Earth. Good food and nutrition for astronauts help to keep their psychology and physiology in good shape. In this paper, solutions will be made on the various alternatives for feeding astronauts in the long term missions to various celestial bodies: Moon, Mars and Venus, where the atmosphere, gravity, soil, radiation and other conditions vary from one to the other and may not support germination, growth and development of plants. Therefore, review will be done on the following: having fore knowledge of how plants will grow on these celestial bodies by simulating their soils; using mathematical/theoretical models to get the growth rate of plants in relation to the gravity available on these celestial bodies using available data from terrestrial growth (1 g growth) and microgravity/microgravity simulations facilities; getting to know how the plants will be grown such as using greenhouse method as a result of the atmosphere and radiation in these celestial bodies; and other various alternatives for growing plants and having the astronauts well-nourished such as using aeroponics and hydroponics methods. A brief discussion will also be done on food choice for astronauts considering psychosocial and cultural factors.
\end{abstract}

Keywords Astronaut $\cdot$ Moon · Mars · Venus $\cdot$ Space food and nutrition $\cdot$ Possible solutions to plant growth

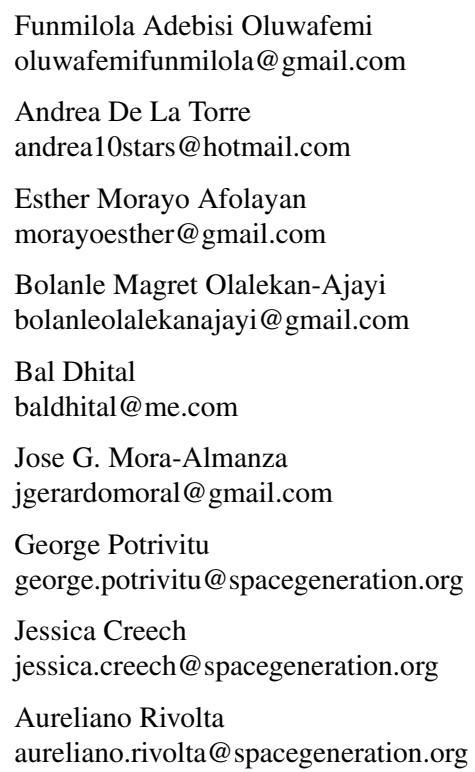




\section{Abbreviations}

NASA National Aeronautics and Space Administration CIP International Potato Center

NASRDA National Space Research and Development Agency

UNOOSA United Nations Office for Outer Space Affairs UV Ultraviolent

\section{Introduction}

There are cultural, scientific, and political imperatives that contribute to the drive to explore space. The cultural imperative is embodied in the innate need of humankind to extend its boundaries and move forward into new domains, in the process gaining a sense of progress and common accomplishment. This urge to explore and advance seems to flow from a survival instinct that is basic to the human species. The scientific imperative derives from humankind's desire to understand its surroundings, whether to satisfy natural curiosity, gain material benefit, or dispel fear of the unknown. This may be another manifestation of the same fundamental characteristic of human nature, since scientific thought, observation and experimentation are well documented throughout recorded history. We now know that certain fundamental and compelling questions of our origins and destiny can only be answered by observing phenomena in deep space and by studying the environments of our solar system [1].

Some of these imperatives include: the prediction of United Nations that by 2050 the Earth's human population will have grown from 7.6 billion to 9.8 billion and by 2100 to 11.2 billion [2]; the sustainability of world's population, the growing pressures on the environment, global food supplies, and energy resources, humanity needs to start planning to leave the safety net of the Earth and look to the stars. Spreading out to one of our next door neighbors, such as the Moon or Mars [3]; in five billion years, our Sun will start to die, expanding as it enters its red giant phase. It will engulf Mercury, Venus, and, even if it does not swell enough to reach Earth, it will still boil off the oceans and heat the surface to temperatures that even the hardiest life forms could not survive. It is hoped that long before any of these natural or man-made terrestrial problems come to pass, humans would have chosen to leave Earth and move to Mars, the Moon or beyond [4]. "If we make it to Mars, we will have answered the question of whether humanity is fated to be a single-planet or multi-planet species", Elon Musk [5] says.

There is this claim that, although the Moon is nearer, making access and communications easier, it is Mars that seems to have captured our imagination for a future human outpost. Much of this is inspired by evidence that it might have once

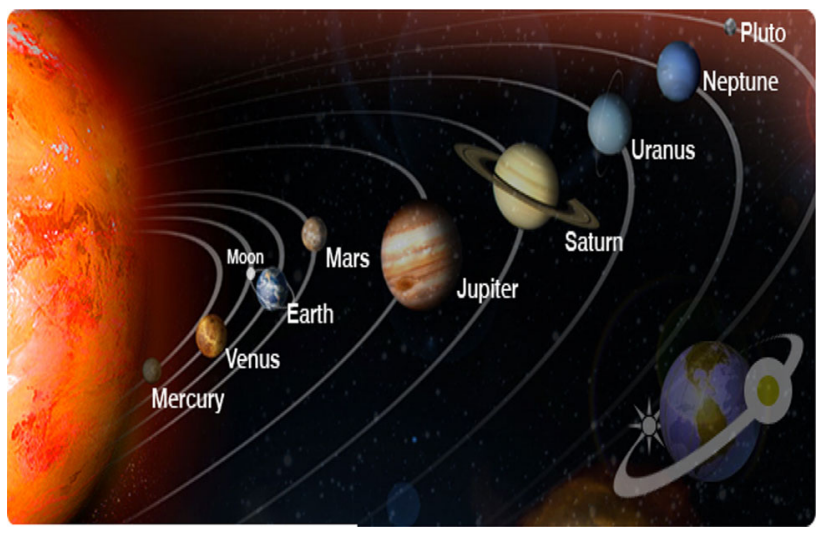

Fig. 1 The solar system

been a world similar to the Earth. Mars is one of the few places in our solar system where life similar to Earth life may be able to survive. This makes it of particular interest to us, but it also makes it a location of special concern for human exploration. The picture of the solar system is seen in Fig. 1.

Space food is a variety of food products, specially created and processed for consumption by astronauts in outer space. As nutrition is the process of providing or obtaining the food necessary for health and growth, space nutrition is therefore, the process of providing or obtaining the food necessary for health and growth in space. Nutrition has played a critical role throughout the history of explorations, and space exploration is no exception. Space explorers have always had to face the problem of how to carry enough food for their journeys as adequate storage space has been a problem. Long-duration spaceflight will require the right amount of nutrient requirements for maintenance of health and protection against the effects of microgravity. Sustaining adequate nutrient intake during space flight is important not only to meet nutrient needs of astronauts but also to help counteract negative effects of space flight on the human body and to avoid deficiency diseases, i.e., food needs to be edible throughout the voyage, and it also needs to provide all the nutrients required to avoid diseases. For example, because of microgravity, astronauts lose calcium, nitrogen, and phosphorus. Therefore, these lost nutrients need to be gained back through food. Space foods usually have the following characteristics: nutritious, light weight, compact, easily digestible, palatable, physiologically appropriate, well packed, quick to serve, easy to clean-up, high acceptability with minimum preparation.

National Aeronautics and Space Administration (NASA) officials in turn are betting that high-tech 3D food printers, using nutrient-laden media as the base material, might help further the goal of eventually reaching Mars. 3D printing can be adjusted on the fly to address both flavor and nutritional demands. Potentially, it could be used to make freshly pre- 
pared food to the crew-member's preferences, customize the foods, and add in specific nutrition over time. That was the idea, separated out ingredients can be taken that are highly stable and then, in a completely automated system, mixed and printed out [6].

Apart from the provision of required nutrients, space nutrition also has many other aspects of impact, including maintenance of endocrine, immune, and musculoskeletal systems. Nutrition and food science research overlap, with integral to many other aspects of space medicine and physiology including psychological health, sleep and circadian rhythmicity, taste and odor sensitivities, radiation exposure, body fluid shifts, and wound healing and to changes in the musculoskeletal, neurosensory, gastrointestinal, hematologic, and immunologic systems. Nutrient intake plays a fundamental role in health maintenance. Good food and nutrition for astronauts help to keep their psychology and physiology in good shape. Therefore, good meals for astronauts have psychosocial and physiology benefits.

Psychosocial and cultural factors are important aspects of nutrition for productive mission and crew morale. Therefore, research is also needed to be done more on this. Spaceflight is associated with many physiological changes, as a result of the microgravity environment, including space motion sickness, fluid shifts, congestion and altered taste and smell. The environment of the spacecraft (including the spacecraft cabin, radiation, lack of ultraviolet light exposure, carbonIVoxide exposure, and the spacesuit atmosphere) can affect nutrition and nutritional requirements for long-duration spaceflight [7]. At the required celestial mission station after the long spaceflight, there will also be challenges on the psychosocial and cultural factors of nutrition.

In this paper, solutions will be made on the various alternatives for feeding astronauts in the long term missions to various celestial bodies: Moon, Mars and Venus, where the atmosphere, gravity, soil, radiation, light and other conditions vary from one to the other and may not support germination, growth and development of plants.

\section{Characteristics of Earth, Moon, Mars and Venus in Relation to Plant Growth}

\subsection{Earth (Control Condition for Planting)}

Gravity is the force that attracts a body towards the centre of the Earth, or towards any other physical body having mass. Gravity is very important as it makes the Earth to retain its atmosphere. The gravity of the Earth is $9.807 \mathrm{~m} / \mathrm{s}^{2}$. The atmosphere of Earth is the layer of gases, commonly known as air, which surrounds the planet Earth. The atmosphere of Earth protects life on Earth by absorbing ultraviolet solar radiation, warming the surface through heat retention (greenhouse effect), and reducing temperature extremes between day and night [8]. On the Earth the daylight available is adequate to grow plants. The availability of a significant atmosphere, and hence greenhouse warming, combined with Earth's distance from the Sun, make Earth's temperature good for plant growth. The atmosphere of Earth therefore makes it possible for lives survival.

Soil is the upper layer of Earth in which plants grow, a black or dark brown material typically consisting of a mixture of organic remains, clay, and rock particles. The most important benefits that the soil provides for the plants are: nutrients, moisture, and aeration and structure. Rich soil contains the primary plant nutrients of nitrogen, phosphorus and potassium along with a host of minor nutrients that help fuel plant growth. Decaying organic matter and minerals within the soil provide these nutrients. Soil that does not contain sufficient nutrients requires fertilizer to add the nutrients needed by the specific plants grown in the soil. Soil acidity, discovered by a pH test, also affects how well nutrients are available to plants. Most plants perform best in soil that has a $\mathrm{pH}$ level near neutral, or $6.0-7.0 \mathrm{pH}$, although some do best in soil with a higher or lower $\mathrm{pH}$ level.

Moisture affects the health of plants and soil. Most garden plants grow best when the soil remains evenly moist, but they do not tolerate soggy or wet conditions. Good soil drains excess water well without drying out too quickly. A soil rich in organic matter, either naturally or from compost amendments, provides drainage and moisture. Some soil contains heavy clay particles, which make it too wet, while other soil is sandy and drains too quickly.

Plant roots need access to oxygen in the soil to thrive, but the soil still must offer enough structure to support the roots. Wet or dense soil suffocates roots, and overly aerated soil gives roots nothing to grasp, making the plants easily uprooted. Turning the soil before planting helps incorporate oxygen into the soil, as does the addition of organic matter such as compost and peat. The largest particles in organic matter break up clay and sand in soil, providing more space for aeration between all of the particles in the soil [9]. Physical and atmospheric properties of the Earth are shown in Table 1.

\subsection{Soil of Mars, Moon and Venus}

The surface and soil of a planetary body holds important clues about its habitability, both in its past and in its future. For example, examining soil features have helped scientists show that early Mars was probably wetter and warmer than it is currently. "Studying soils on our celestial neighbors' means to individuate the sequence of environmental conditions that imposed the present characteristics to soils, thus helping reconstruct the general history of those bodies". In 2008, NASA's Phoenix Mars Lander performed the first wet chem- 
Table 1 Physical and atmospheric properties of the earth

\begin{tabular}{ll}
\hline Physical properties & Value \\
\hline Radius & $6371 \mathrm{~km}$ \\
Gravity & $9.78 \mathrm{~m} / \mathrm{s}^{2}$ \\
Density & $5.51 \mathrm{~g} / \mathrm{cm}^{3}$ \\
Surface area & $510,072,000 \mathrm{~km}^{2}$ \\
Distance from sun & $149,600,000 \mathrm{~km}$ \\
Length of day & $1 \mathrm{~d}(\mathrm{i} . \mathrm{e} ., 24 \mathrm{~h})$ \\
Moons & 1 \\
Volume & $108.321 \times 1010 \mathrm{~km} 3$ \\
Mass & $5.972 \times 1024 \mathrm{~kg}$ \\
Orbital period & $365 \mathrm{days}$ \\
\hline Atmospheric properties & Value \\
\hline Average surface temperature & $16{ }^{\circ} \mathrm{C}$ \\
Average surface pressure & $101.3 \mathrm{kPa}$ \\
Composition (mole & \\
fractions) & \\
CarbonIVoxide & $0.0397 \%$ \\
Nitrogen & $78.084 \%$ \\
Argon & $0.9340 \%$ \\
Oxygen & $20.946 \%$ \\
CarbonIIoxide & $0.00001 \%(0.1 \mathrm{ppmv})$ \\
Water vapor (over full atm.) & $\sim 0.25 \%$ \\
Water vapor (locally) & $0.001-5 \%$ \\
Nitric oxide & $0.0000325 \%(0.325 \mathrm{ppmv})$ \\
Molecular hydrogen & $0.000055 \%(0.55 \mathrm{ppmv})$ \\
Neon & $0.001818 \%(18.18 \mathrm{ppmv})$ \\
Krypton & $0.000114 \%(1.14 \mathrm{ppmv})$ \\
Xenon & $0.000009 \%(0.09 \mathrm{ppmv})$ \\
Methane & $0.000179 \%(1.79 \mathrm{ppmv})$ \\
\hline
\end{tabular}

istry experiment using Martian soil. Scientists who analyzed the data said the Red Planet appears to have environments more appropriate for sustaining life than what was expected, environments that could 1 day allow human visitors to grow crops. Researchers found traces of magnesium, sodium, potassium and chloride, and the data also revealed that the soil was alkaline ( 8 or 9), a finding that challenged a popular belief that the Martian surface was acidic. This type of information, obtained through soil analyses, becomes important in looking toward the future to determine which planet would be the best candidate for sustaining human colonies.

Certini and his colleague Riccardo Scalenghe from the University of Palermo, Italy, recently published a study in Planetary and Space Science that makes some encouraging claims. They say the surfaces of Venus, Mars and the Moon appear suitable for agriculture. On Venus, Mars and the Moon, weathering occurs in different ways. Venus has a dense atmosphere at a pressure that is 91 times the pressure found at sea level on Earth and composed mainly of
carbonIVoxide and sulphuric acid droplets with some small amounts of water and oxygen. Mars is currently dominated by physical weathering caused by meteorite impacts and thermal variations rather than chemical processes. The red colour of the Martian soil comes from iron oxide (rust or hematite) in its soil [10] with $\mathrm{pH}$ of 8 . On the moon, a layer of solid rock is covered by a layer of loose debris. The weathering processes seen on the Moon include changes created by meteorite impacts, deposition and chemical interactions caused by solar wind, which interacts with the surface directly. The Moon rather has lunar regolith. Regolith is inorganic and lies like a blanket over unfragmented rock. It is typically made up of material that is weathered away from the underlying rock. The soil is a zone of plant growth and is a thin layer of mineral matter that normally contains organic material and is capable of supporting living plants [11].

Some scientists, however, feel that weathering alone is not enough and that the presence of life is an intrinsic part of any soil. One of the primary uses of soil on another planet would be to use it for agriculture, to grow food and sustain any populations that may 1 day live on that planet. This is one of the biggest challenges needed to be solved to enable humans to live on another planet. Some scientists, however, are questioning whether soil is really a necessary condition for space farming $[12,13]$. The pictures of the Martian soil, Moon regolith and the Venus soil/regolith are seen in Figs. 2, 3 and 4.

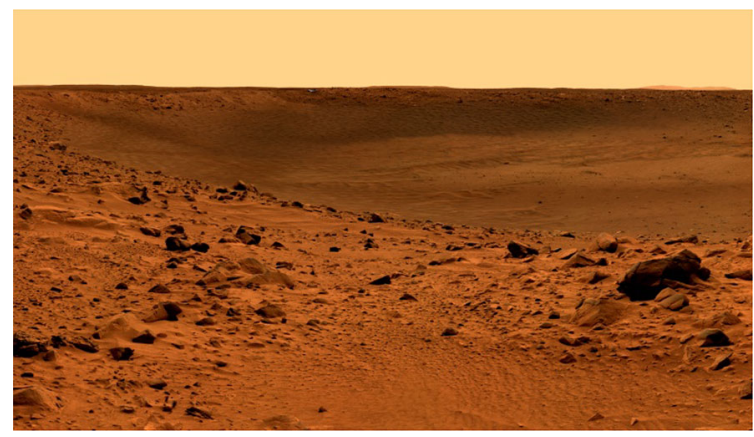

Fig. 2 Martian soil

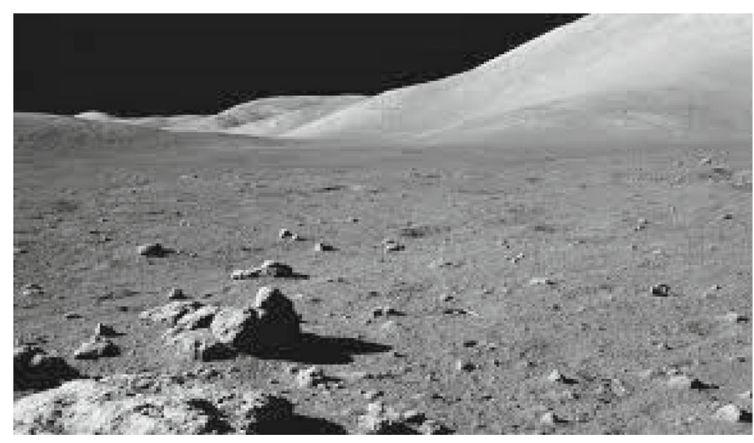

Fig. 3 Moon Regolith 


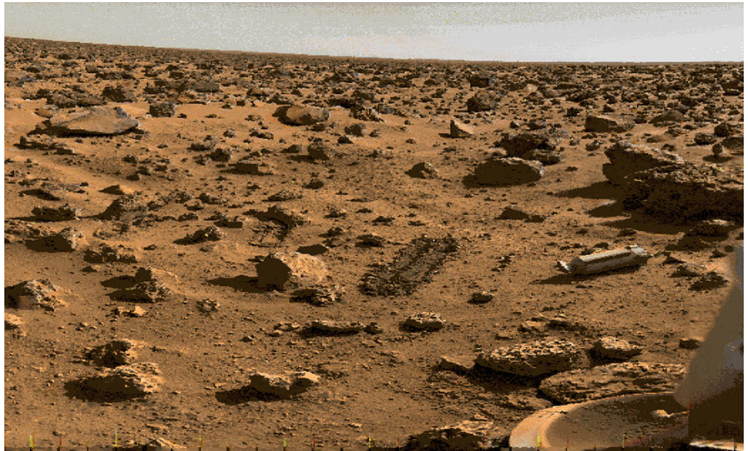

Fig. 4 Venus soil/Regolith

\subsection{Mars}

Mars is often seen as the next logical step in human exploration of the Solar System. This interest in Mars is linked with its resources and environment, which could help sustain long term human presence, and answer the crucial question, "Can life arise outside our planet?". In the past, Mars presented environmental conditions that might have been able to support life as known on Earth, including liquid water and a dense atmosphere. However, the evolution of Mars has rendered its surface environment inhospitable for all currently known life forms. With this increased enthusiasm and excitement about mars mission, it is easy to disregard or forget the challenges and difficulties that such a feat entail. Even though more than 50 years have passed since mankind first ventured into space, the challenge of putting a man on Mars presents additional complications that the space industry has not faced before. The idea of a one-way mission (also known as "Mars to stay") was first proposed in 1996 [14] and has, since then, led to a several subsequent proposals that first mission to Mars should be a settlement, not a visit [15]. Despite slight variations in the content of these proposals, they all rest on several common arguments: A one-way mission to Mars (i.e., not involving a return of the crew to Earth) makes sense because, compared to a round-trip mission, it requires less mass at launch and lower initial costs. This could help mankind reach Mars earlier. A one-way mission does, however, require a different approach to the design of the habitat modules and present additional risks. One of the major risks involves food and nutrition for the space explorers. This means farming their food on another planet that has a very different ecosystem than Earth's.

Mars' gravity is $3.711 \mathrm{~m} / \mathrm{s}^{2}$ which is $38 \%$ that of Earth, it has sub-zero mean temperature (on average $-63{ }^{\circ} \mathrm{C}$ ), thin non-breathable $\mathrm{CO}_{2}$-rich atmosphere, high Ultraviolent (UV) radiation and savage global dust storms, low pressure atmosphere and lacks readily available liquid water (due to its low pressure to retain water in a liquid form, water instead sublimates to a gaseous state, hence Mars has no oceans and hence no "sea level"). The rotational period and seasonal cycles of Mars are likewise similar to those of Earth [16]. The lengths of the Martian seasons are about twice those of Earth's, as Mars's greater distance from the Sun leads to the Martian year being about two Earth years long [17]. Has the most clement environment in the solar system after the Earth. It also has the potential to contain habitable environments for life. Since to survive, terrestrial-type life needs an environment with a source of liquid water, organic molecules, and a source of energy.

The first 'Martians' will, therefore, be two kinds: plants and humans, who are actually ideal companions. Gardens are the key to settling on Mars as they could help to recycle nutrients, and use the carbon from the toxic Martian atmospheric to produce oxygen through photosynthesis for humans to breathe. Gardens could even, in the long term, provide building materials such as wood and bamboo, and would improve the morale and wellbeing of the crew. The lack of a significant atmosphere, and hence very little greenhouse warming, combined with Mars' distance from the Sun, make Mars a very cold place indeed. On Mars, near the equator, the duration of daylight is about $12 \mathrm{~h}$, followed by approximately $12 \mathrm{~h}$ of darkness [18]. One of the major hazards involved in planting on Mars will be associated with the exposure to high UV-radiation. High UV-radiation has been shown to be harmful to living organisms, damaging DNA, proteins, lipids and membranes. Therefore, plants exposed to these radiations are at risk and also risky to eat. Physical and atmospheric properties of Mars are shown in Table 2.

\subsection{Moon}

The Moon is an astronomical body that orbits planet Earth, being Earth's only permanent natural satellite [19]. It is the second brightest object in the sky after the Sun. It orbits around the Earth once per month. The proximity of the Earth to the Moon makes the Moon an important step beyond Earth orbit [1]. On average, the distance from Earth to the Moon is about $384,400 \mathrm{~km}$ [20]. Human explorers will conduct scientific research, identify and develop resources, gain experience with establishing human outposts on other planetary bodies, and validate techniques for exploration of more distant destinations [1]. Such planetary body is the Moon, because it is small and it is readily accessible. The Moon may represent a potential resource for commercial exploitation. There have been many proposals to export lunar resources for use on Earth as well as proposals to use lunar-generated energy and to use the Moon for education, entertainment or space tourism [19] i.e., focusing on the resource exploitation and commercialization. In addition to the Moon's intrinsic science value and its potential importance as an observational platform and a resource node, the Moon provides several additional benefits to a stepping-stone approach into the solar system. 
Table 2 Physical and atmospheric properties of Mars

\begin{tabular}{|c|c|}
\hline Physical properties & Value \\
\hline Radius & 3396 km \\
\hline Gravity & $3.711 \mathrm{~m} / \mathrm{s}^{2}$ \\
\hline Density & $3.93 \mathrm{~g} / \mathrm{cm} 3$ \\
\hline Surface area & $144,798,500 \mathrm{~km}^{2}$ \\
\hline Distance from Sun & $227,900,000 \mathrm{~km}$ \\
\hline Length of day & $1 \mathrm{~d} 0 \mathrm{~h} 40 \mathrm{~m}$ \\
\hline Moons & 2 (Phobos, Deimos) \\
\hline Volume & $\begin{array}{l}1.6318 \times 1011 \mathrm{~km}^{3}(0.151 \\
\text { Earths') }\end{array}$ \\
\hline Mass & $6.4185 \times 1023 \mathrm{~kg}(0.107$ Earths') \\
\hline Orbital period & 687 (Earth) days. \\
\hline Atmospheric properties & Value \\
\hline Surface temperature & $\begin{array}{l}\operatorname{Min}\left(-143^{\circ} \mathrm{C}\right) \\
\operatorname{Mean}\left(-63^{\circ} \mathrm{C}\right) \\
\operatorname{Max}\left(35^{\circ} \mathrm{C}\right)\end{array}$ \\
\hline \multicolumn{2}{|l|}{$\begin{array}{l}\text { It has a cold and } \\
\text { desert-like surface }\end{array}$} \\
\hline Surface pressure & $0.636 \mathrm{kPa}$ \\
\hline \multicolumn{2}{|l|}{$\begin{array}{l}\text { Composition (mole } \\
\text { fractions) }\end{array}$} \\
\hline CarbonIVoxide & $95.32 \%$ \\
\hline Nitrogen & $2.7 \%$ \\
\hline Argon & $1.6 \%$ \\
\hline Oxygen & $0.13 \%$ \\
\hline CarbonIIoxide & $0.08 \%$ \\
\hline Water vapor & $210 \mathrm{ppm}$ \\
\hline Nitric oxide & $100 \mathrm{ppm}$ \\
\hline Molecular hydrogen & $15 \mathrm{ppm}$ \\
\hline Neon & $2.5 \mathrm{ppm}$ \\
\hline Krypton & $300 \mathrm{ppb}$ \\
\hline Xenon & $80 \mathrm{ppb}$ \\
\hline Methane & $10 \mathrm{ppb}$ \\
\hline HDO & $850 \mathrm{ppb}$ \\
\hline Formaldehyde & $130 \mathrm{ppb}$ \\
\hline Hydrogen peroxide & $18 \mathrm{ppb}$ \\
\hline
\end{tabular}

In the Moon, there is sharp contrast conditions between day and night, the compositions during the day may be somewhat different from the atmosphere at night. Although the atmosphere of the Moon is very thin, the Moon does have an atmosphere. The composition is not well known, but it is estimated to consist in atoms per cubic centimeter of Helium, Neon, Hydrogen, Argon, Methane, Ammonia, CarbonIVoxide, with trace amounts of Oxygen, Aluminum, Silicon, Phosphorus, Potassium, Sodium, and Magnesium ions.
Even though the Moon has an atmosphere, it is too thin to breathe and includes compounds not good in the lungs [21]. However, the Moon keeps very little of the atmosphere it receives. Any gas it momentarily captures escapes from the surface very rapidly [22]. The surface of the Moon is baldly exposed to cosmic rays and solar flares, and some of that radiation is very hard to stop with shielding. Furthermore, when cosmic rays hit the ground, they produce a dangerous spray of secondary particles right at the feet [23]. Therefore, plants exposed to these radiations are at risk and also risky to eat. The main elements needed for life support-oxygen, hydrogen, nitrogen, and carbon - are available in the lunar regolith, albeit at extraordinarily low concentrations except for oxygen, which is tightly bound chemically within the minerals.

The Moon as a natural space station provides a benign environment with one-sixth gravity for human utilization and exploration. The gravity of the Moon is $1.62 \mathrm{~m} / \mathrm{s}^{2}$. There is some evidence that the adverse effects of weightlessness on the human body may be absent or substantially reduced in lunar gravity [1]. Physical and atmospheric properties of the Moon are shown in Table 3.

Table 3 Physical and atmospheric properties of the Moon

\begin{tabular}{ll}
\hline Physical properties & Value \\
\hline Radius & $1737 \mathrm{~km}$ \\
Gravity & $1.62 \mathrm{~m} / \mathrm{s}^{2}$ \\
Density & $3.34 \mathrm{~g} / \mathrm{cm}^{3}$ \\
Surface area & $38,000,000 \mathrm{~km}^{2}$ \\
Distance from Sun & $147,000,000 \mathrm{~km}$ \\
Length of day & 27.3 days \\
Volume & 21.9 billion $\mathrm{km}^{3}$ \\
Mass & $7.35 \times 10^{22} \mathrm{~kg}$ \\
Orbital period & $27($ Earth $)$ days \\
\hline Atmospheric properties & Value \\
\hline Average surface temperature & $107^{\circ} \mathrm{C}$ during day \\
& $-153^{\circ} \mathrm{C}$ at night \\
Surface pressure (night) & $3 \times 10^{-15}$ bar $\left(2 \times 10^{-12}\right.$ torr) \\
Composition (not & \\
including trace) in & \\
atoms per cubic & \\
centimeter & 17 \\
Argon & \\
Helium & \\
Neon & $20,000-100,000$ \\
Sodium & $5000-30,000$ \\
Potassium & 20,000 \\
Hydrogen & 70 \\
Nitric oxide & \\
\end{tabular}




\subsection{Venus}

Venus is the second planet from the Sun, and considered in many ways to be a twin planet of Earth. It has a similar size, mass, density and gravity, as well as a very similar chemical composition. In other ways, Venus is very different than Earth, with its high surface temperature, crushing pressure, and poisonous atmosphere. One of the strange characteristics of Venus is that it's actually rotating backwards from the rest of the planets. Seen from above, all of the planets rotate counter-clockwise, but Venus turns clockwise on its axis. Gravity on Venus is $90 \%$ the gravity on Earth. The gravity would feel very similar to Earth. Furthermore, the atmospheric pressure on the surface of Venus is 92 times Earth pressure. Venus' atmosphere is composed almost entirely of carbonIVoxide, and its thick atmosphere acts like a blanket, keeping Venus so hot. Nitrogen exists in small doses in its atmosphere and so do clouds of sulfuric acid. Therefore, the atmosphere absorbs near-infrared radiation, making it easy to observe. The air of Venus is so dense that the small traces of nitrogen are four times that amount found on Earth, although nitrogen makes up more than three-fourths of the terrestrial atmosphere. This composition causes a runaway greenhouse effect that heats the planet even hotter than the surface of Mercury, although Venus lies farther from the Sun, i.e., Venus is not the closest planet to the Sun, it is still the hottest. It has a thick atmosphere full of the greenhouse gas carbonIVoxide and clouds made of sulfuric acid. The gas traps heat and keeps Venus toasty warm. When the rocky core of Venus formed, it captured much of the gas gravitationally. In addition to warming the planet, the heavy clouds shield it, preventing visible observations of the surface and protecting it from bombardment by all the largest meteorites. Venus has no water on its surface, and very little water vapor in its atmosphere. The clouds of Venus appear to be bright white or yellow and are capable of producing lightning much like the clouds on Earth. Most of the surface of Venus is covered by smooth volcanic plains, and its dotted with extinct volcanic peaks and impact craters [24].

Despite the harsh conditions on the surface, the atmospheric pressure and temperature at about $50 \mathrm{~km}$ to $65 \mathrm{~km}$ above the surface of the planet is nearly the same as that of the Earth, making its upper atmosphere the most Earth-like area in the Solar System, even more so than the surface of Mars. Due to the similarity in pressure and temperature and the fact that breathable air ( $21 \%$ oxygen, $78 \%$ nitrogen) is a lifting gas on Venus in the same way that helium is a lifting gas on Earth, the upper atmosphere has been proposed as a location for both exploration and colonization. This brings about the
Table 4 Physical and atmospheric properties of Venus

\begin{tabular}{ll}
\hline Physical properties & Value \\
\hline Radius & $\begin{array}{c}6052 \mathrm{~km}(95 \% \text { the size of the } \\
\text { Earth })\end{array}$ \\
Gravity & $8.87 \mathrm{~m} / \mathrm{s}^{2}$ \\
Density & $5.24 \mathrm{~g} / \mathrm{cm}^{3}$ \\
Surface area & $460,200,000 \mathrm{~km}^{2}$ \\
Distance from Sun & $108,000,000 \mathrm{~km}$ \\
Length of day & $116 \mathrm{~d} 18 \mathrm{~h} 0 \mathrm{~m}$ \\
Moons & None \\
Volume & $9.38 \times 10^{11} \mathrm{~km}(86 \%$ Earths') \\
Mass & $4.87 \times 10^{24} \mathrm{~kg}(82 \%$ Earths') \\
Orbital period & $225($ Earth $) \mathrm{days}$ \\
\hline Atmospheric properties & Value \\
\hline Surface temperature & $467{ }^{\circ} \mathrm{C}$ \\
Surface pressure & $9300 \mathrm{kPa}$ \\
Composition & \\
CarbonIVoxide & $96 \%$ \\
Nitrogen & $3.5 \%$ \\
SulfurIVoxide & $150 \mathrm{ppm}$ \\
Argon & $70 \mathrm{ppm}$ \\
Water vapor & $20 \mathrm{ppm}$ \\
CarbonIIoxide & $17 \mathrm{ppm}$ \\
Helium & $12 \mathrm{ppm}$ \\
Neon & $7 \mathrm{ppm}$ \\
Hydrogen chloride & $0.1-0.6 \mathrm{ppm}$ \\
Hydrogen fluoride & $0.001-0.005 \mathrm{ppm}$ \\
\hline & \\
\hline & \\
\hline
\end{tabular}

question, "Should we go to Venus instead of Mars?" Unlike Mars' thin and useless atmosphere, Venus' thick atmosphere protects against radiation. Cue a few plans to live in a "cloud city" [25].

As the Venusian atmosphere supports opaque clouds made of sulfuric acid, this makes optical Earth-based and orbital observation of the surface impossible. Information about the topography has been obtained exclusively by radar imaging. Venus rotation is very slow. It takes about 243 Earth days to spin around just once because it's so close to the Sun, a year goes by fast. It takes 225 Earth days for Venus to go all the way around the Sun. That means that a day on Venus is a little longer than a year on Venus. Since the day and year lengths are similar, on the Earth, the Sun rises and sets once each day, but on Venus, the Sun rises every 117 Earth days. Since Venus rotates backwards, the Sun rises in the west and sets in the east. Physical and atmospheric properties of Venus are shown in Table 4. 


\section{Alternatives for Feeding Astronauts in Long term Missions to Selected Celestial Bodies}

Fulfillment of space exploration mission is key, but much more important are the lives of the explorers. Keeping the astronauts alive, jolly and healthy for long term manned mission has recently being a major and important research area. A major contribution seems to be the food they eat. For short term space manned missions and in spaceflight discussed, astronauts food could be taken along with them from Earth, but for manned missions to the Moon, Mars and Venus which are the current research destinations for long term space missions, they must find a means for their nutrition for survival, as most of these proposed missions have being designed to be one-way missions whereby the astronauts will not come back to the Earth.

The life support system for missions includes food and water production. In the space habitat, plants and humans are actually ideal companions. Humans consume oxygen and release carbonIVoxide. Plants return the favour by consuming carbonIVoxide and releasing oxygen. Humans can use edible parts of plants for nourishment, while human waste and inedible plant matter can (after being broken down by microbes in tanks called bioreactors) provide nutrients for plant growth. These plants can even provide medicine. However, how gravity, light, atmosphere, soil, radiation and other conditions affect the plant's ability to grow needs to be researched and discussed.

\subsection{Possible Solutions}

How can the space explorers survive indefinitely on other celestial bodies without growing their food? It costs $\$ 80,000$ to ship four litres of water to the Moon! Let alone the logistics, of shipping water and food to Mars. As on Earth, growing on other celestials require the same basic ingredients for plants to grow. It takes soil (with nutrient), water, oxygen and a good amount of light to get it out of the ground. Since all of these requirements are not constant in each of the selected celestials, a series of solutions are proposed for the basic aspects of a possible development of plants and food to feed the astronauts when the day of colonization arrives.

\subsubsection{Soil Simulations}

When humans will settle on the Moon or Mars or Venus, they will have to eat there. Food may be shipped, but an alternative could be to cultivate plants in native soils. This will also reduce costs. Having fore knowledge of how plants will grow on Moon, Mars and Venus by simulating their soils is one of these solutions. Reports on the first large scale-controlled experiment to investigate the possibility of growing plants in

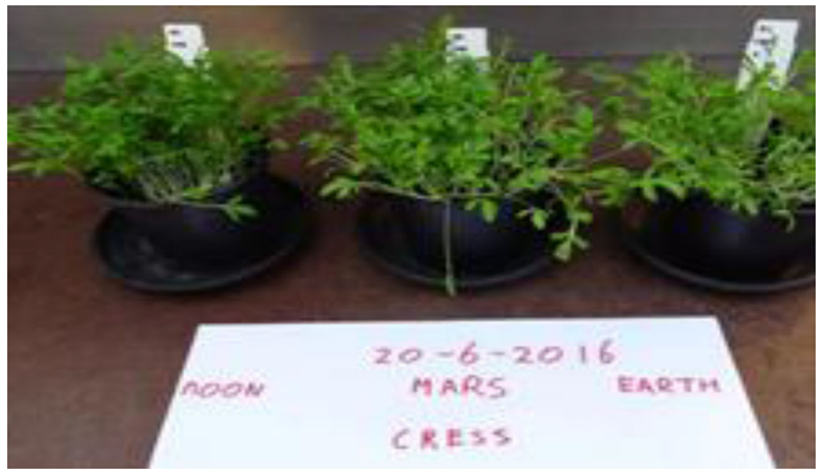

Fig. 5 Comparison between Terrestrial, Lunar and Martian soil

Mars and Moon soil simulant shows that plants are able to germinate and grow on both Martian and Moon soil simulant for a period of 50 days without any addition of nutrients (see Fig. 5). Growth and flowering on Mars regolith simulant (containing a chemical composition almost identical to that of the red planet) [26] was much better than on Moon regolith simulant and even slightly better than the control; nutrient poor river soil. Plants such as: asparagus, potatoes and marigolds have already been shown to grow in Marslike soils. Seeds of radish, alfalfa, and mung bean have been observed to sprout in a $\mathrm{CO}_{2}$-rich atmosphere like that on Mars. Other examples are: reflexed stonecrop (a wild plant); the crops tomato, wheat, and cress; and the green manure species field mustard performed particularly well. The latter three flowered, and cress and field mustard also produced seeds. Their results show that in principle it is possible to grow crops and other plant species in Martian and Lunar soil simulants.

Weiger et al. [27] reported that in general, germination percentage is highest on Martian soil simulant and lowest on the Moon soil simulant. Leaf forming occurred most on Martian soil simulant and least on Moon soil simulant. This trend is also present for species that form flowers or seeds. Additionally, for the percentage plants still alive after 50 days, Martian soil simulant performed best than moon soil simulant. Martian soil simulant also performed better than Earth soil for most species. The biomass at the end of the experiment was significantly higher for eleven out of the fourteen species on Martian soil simulant as compared to both other soils. The biomass for Earth and Moon soil simulant is often quite similar although for nine species the biomass increment on Earth soil was significantly higher than on moon soil simulant. Apparently, in general, plants were able to develop at the same rate on Martian and Earth soil simulants, but biomass increment was much higher on Mars simulant. This is reflected in both below and above ground biomass, although there are differences at the species level. On average, species in Martian soil simulant performed significantly better than plants in Earth soil with respect to biomass incre- 


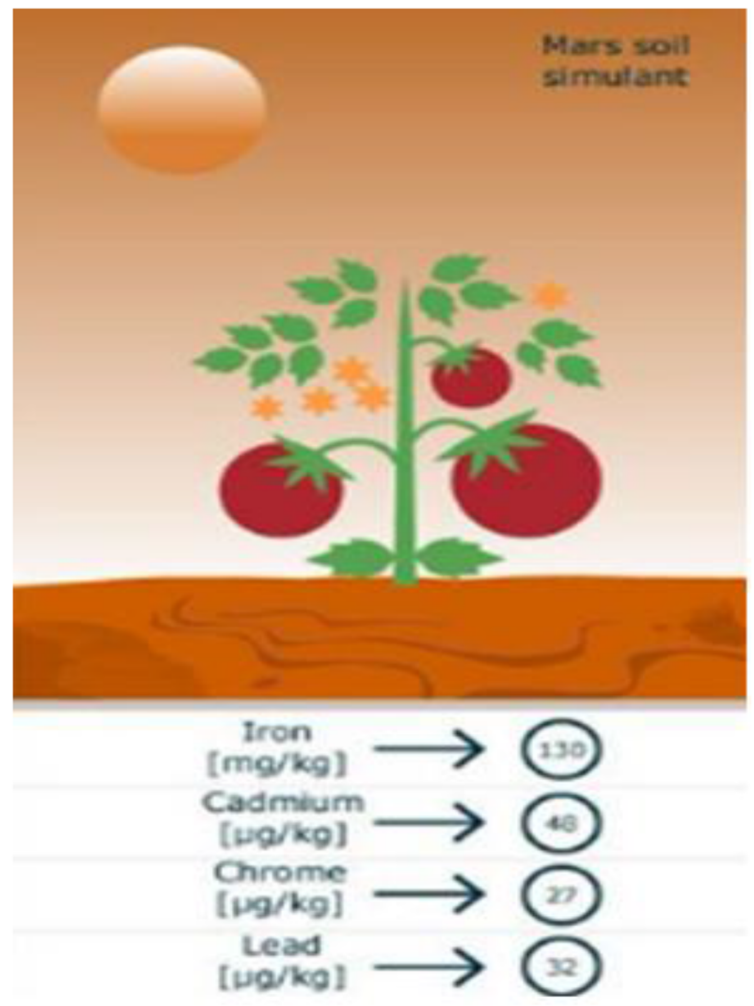

Fig. 6 Potato grown on simulated Martian soil with the corresponding levels of heavy metals

ment. The Mars soil simulant resembles loess-like soils from Europe and holds water better than the other two soils. Moon soil simulant dried out fastest [27].

Wieger Wamelink from Wageningen University, who is a Dutch environmentalist has been experimenting with these crops on Martian and lunar soil for over 3 years, with the intention of checking whether it was safe to eat them. Now, in his last harvest of tomatoes and potatoes, he determined that the levels of heavy metals in these vegetables are safe to be consumed by humans (see Fig. 6). A series of investigations have been carried out that conclude that potatoes, peanuts, strawberries, and tomatoes are the easiest to reproduce in Martian soil.

Use of CubeSats (Closed System) Another method adapted with the use of simulation of soil has also being discovered. The International Potato Center (CIP) launched a series of experiments to discover if potatoes can grow under Mars atmospheric conditions and thereby prove they are also able to grow in extreme climates on Earth. This Phase Two effort of CIP's proof of concept experiment to grow potatoes in simulated Martian conditions began on February 14, 2016 when a tuber was planted in a specially constructed CubeSat contained environment built by engineers from University of Engineering and Technology (UTEC) in Lima based upon designs and advice provided by the National Aeronautics and Space Administration in Ames Research Center (NASA ARC), California. Preliminary results are positive [28].

The CubeSat houses a container holding soil and the tuber. Inside this hermetically sealed environment the CubeSat delivers nutrient rich water, controls the temperature for Mars day and night conditions and mimics Mars air pressure, oxygen and carbonIVoxide levels. Sensors constantly monitor these conditions and live streaming cameras record the soil in anticipation of the potato sprouting [28]. CIP scientists concluded that future Mars missions that hope to grow potatoes will have to prepare the soil with a loose structure and nutrients to allow the tubers to obtain enough air and water to allow it to tuberize [28].

One of the future challenges to produce food in a Mars environment will be the optimization of resources through the potential use of the Martian substratum for growing crops as a part of bioregenerative food systems. In vitro plantlets from 65 potato genotypes were rooted in peat-pellets substratum and transplanted in pots filled with Mars-like soil from La Joya desert in Southern Peru. The Mars-like soil was characterized by extreme salinity (an electric conductivity of 19.3 and $52.6 \mathrm{dS} \mathrm{m}^{-1}$ under $1: 1$ and saturation extract of the soil solution, respectively) and plants grown in it were under sub-optimum physiological status indicated by average maximum stomatal conductance $<50 \mathrm{mmol} \mathrm{H}_{2} \mathrm{O}$ $\mathrm{m}^{-2} \mathrm{~s}^{-1}$ even after irrigation. $40 \%$ of the genotypes survived and yielded (0.3-5.2 $\mathrm{g}$ tuber plant $\left.{ }^{-1}\right)$ where CIP.397099.4, CIP.396311.1 and CIP.390478.9 were targeted as promising materials with 9.3, 8.9 and $5.8 \%$ of fresh tuber yield in relation to the control conditions. A combination of appropriate genotypes and soil management will be crucial to withstand extreme salinity [29].

The experiment conducted by CIP using the CubeSat and simulated Martian soil can be repeated using the Lunar and Venus regolith.

\subsubsection{Solutions to Plant Growth Against the Atmospheric and Radiation Challenges (Environmental)}

The most efficient processes for the development of crops on the selected celestials can be done through closed, controlled or soilless cultivation systems as a result of the unfavorable environmental conditions. The atmospheric conditions and the radiation can not support germination, growth and development of plants.

Greenhouse Method Mars has strong potential to eventually support human life because of its close proximity to the Sun and it atmospheric composition. One critical factor to assess is the potential to support and sustain plant growth on Mars. This would be achieved by setting up a greenhouse that can manipulate Mars' atmosphere to mimic Earth's. To 


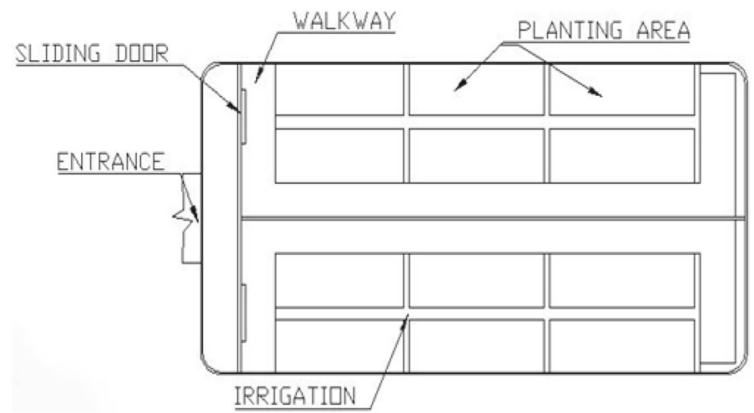

Fig. 7 Single greenhouse layout

achieve the goal of growing plants on Mars, a greenhouse will have to be implemented to combat the unfavorable conditions. The main conditions that will need to be altered are the water, atmosphere, temperature, and lighting. Use of greenhouse method is the alteration of the environment to meet the growth requirements of plants. Addition of fertilizer will be required to provide significant nutrient elements that are lacking in the soil. As the soil will still be used to plant. An ideal plant environment is a greenhouse where all vegetal organisms' needs are supplied within optimal water, light and temperature ranges, according to the space environmental conditions [30].

The water will need to be harvested and desalinated before it can be used in the greenhouse. The atmosphere within the greenhouse can be manipulated by carbonIVoxide generators and irrigation systems. A Martian greenhouse will need to be well insulated to avoid huge temperature drops at night. Perhaps a combination of passive greenhouse heating during the day, supplemented by electrical heating and lighting at night will be required to provide a suitable growing environment for plants to be grown on Mars. Collecting and storing solar energy is an extremely inefficient process. A major fraction of the energy is lost as heat long before it is made available as light energy for plant growth [17].

Greenhouse will also be needed for Moon and Venus agriculture. NASA's growth chamber, 'Veggie [31]', serves as a prototype for the greenhouses that will be required for an ongoing settlement on the Moon or on Mars, and has yielded strong results, with a whole variety of plants having grown successfully, including: onions, cucumbers, bok choy, and lettuce $[32,33]$.

For the greenhouse structure, the types of structures that might be used for plant production on Mars vary from small automatically deployed structures for research purposes to larger structures that would be used to grow plants as part of a manned expedition. The structural requirements will vary depending on the size and purpose of greenhouses, but the functions necessary for successful plant growth will be similar regardless of size [34] (see Figs. 7 and 8).

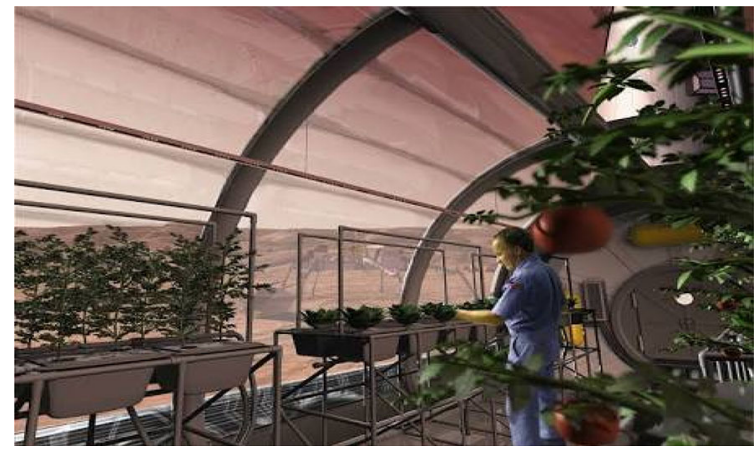

Fig. 8 Greenhouse by NASA

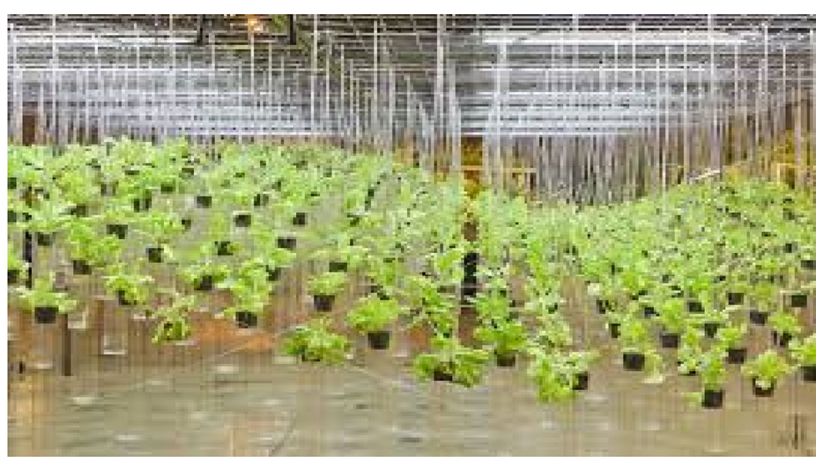

Fig. 9 Hydroponic method of plant farming

Hydroponics and Aquaponics Hydroponic is a plant farming method of growing plants inside an enclosed structure using mineral nutrients solution in water without soil, but in a selected growing medium where the lighting, temperature, and nutrients are closely regulated (see Fig. 9). In hydroponic technique, water is used to transmit nutrients to plants (see Fig. 10). Hydroponics is a subset of hydroculture. Soil to support life in space is not being found, and the logistics of transporting soil are impractical, hydroponics could hold the key to the future of space exploration. Terrestrial plants maybe grown with their roots in the mineral nutrient solution only (liquid hydroponic systems) or in an inert medium, such as perlite, mineral wool, gravel, expanded clay pebbles or coconut husk (aggregate hydroponic systems). The benefits of hydroponics in space are twofold: it offers the potential for a larger variety of food, and it provides a biological aspect, called a bioregenerative life support system. This simply means that as the plants grow, they will absorb carbonIVoxide and stale air and provide renewed oxygen through the plant's natural growing process. This is important for long range habitation on other planets [35].

Aquaponics The term aquaponics is a portmanteau of the terms aquaculture and hydroponic agriculture. Aquaponics refers to any system that combines conventional aquaculture (raising aquatic animals such as snails, fish, crayfish 
Fig. 10 Water is used to transmit nutrients to plants

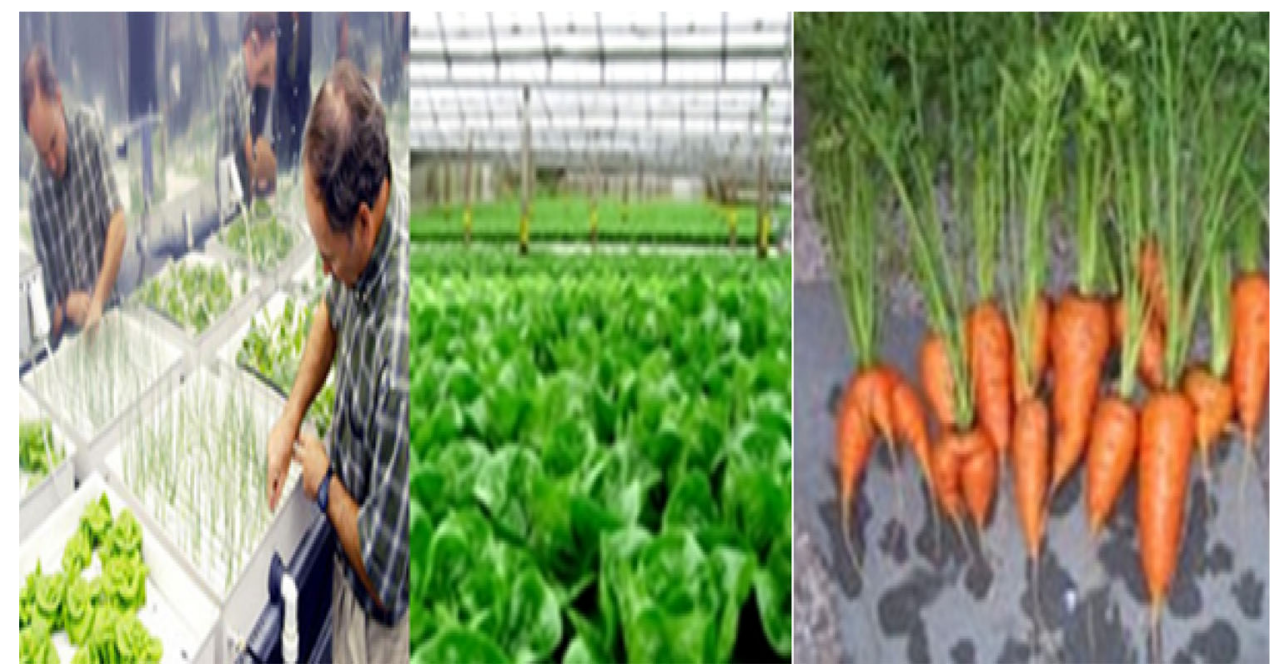

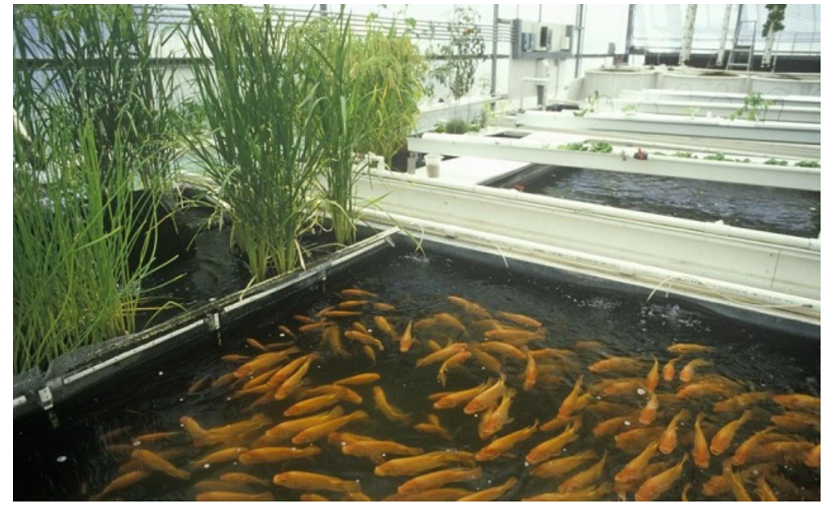

Fig. 11 Aquaponics

or prawns in tanks) with hydroponics (cultivating plants in water) in a symbiotic environment (see Figs. 11 and 12). In normal aquaculture, excretions from the animals being raised can accumulate in the water, increasing toxicity. In an aquaponic system, water from an aquaculture system is fed to a hydroponic system where the by-products are broken down by nitrifying bacteria initially into nitrites and subsequently into nitrates that are utilized by the plants as nutrients. The water is then recirculated back to the aquaculture system. As existing hydroponic and aquaculture farming techniques form the basis for all aquaponic systems, the size, complexity, and types of foods grown in an aquaponic system can vary as much as any system found in either distinct farming discipline [36]. Thanks to its automatic recirculating system, aquaponics does not require much monitoring or measuring".

The main difficulty in setting up this system in deep space is the time of the establishment of this ecosystem. Indeed, modules containing plants and fish should be sent before the arrival of humans. So, during the trip and waiting for early humans, fish and plants will begin to grow and therefore save

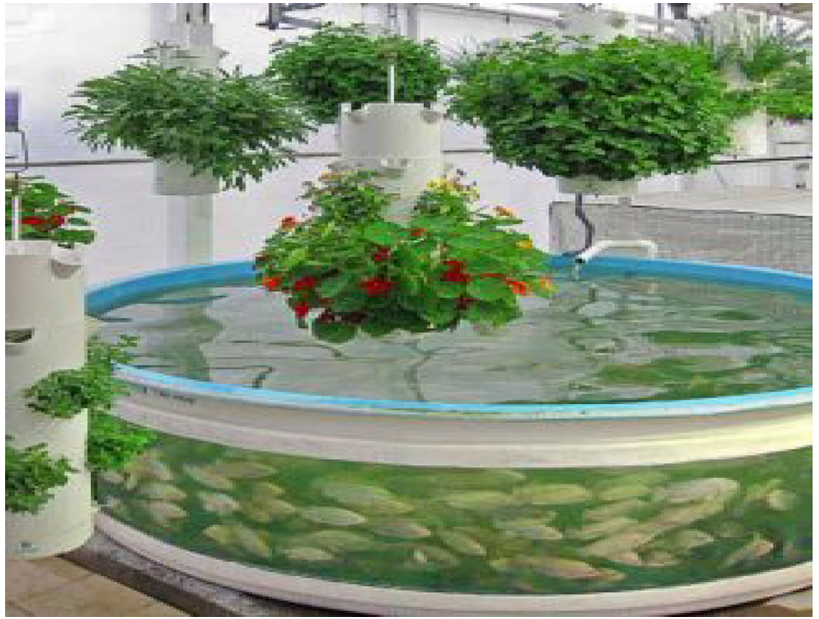

Fig. 12 Aquaponics combines aquaculture and hydroponic agriculture aquaponics

time for growth. These modules will be fully autonomous in the first phase of the cycle, finally, astronauts will complete the loop by bringing the last pieces of the ecosystem, composters, their consumption, and waste [37]. A completely stand-alone system can be created that will provide food self-sufficiency and protection for early settlers through this essential resource. The technology to implement such an ecosystem is now known and used automated on earth so it can be used on Mars [37].

Aeroponics Aeroponic is the process of growing plants in an air or mist environment where roots are continuously or discontinuously kept saturated with fine drops of nutrients solution without the use of soil or an aggregate medium (see Fig. 13). Aeroponics is a soilless cultivation process that uses little water. Scientists have been experimenting with the method since the early 1940s, and aeroponics systems have been in use on a commercial basis since 1983. In 1997, NASA 


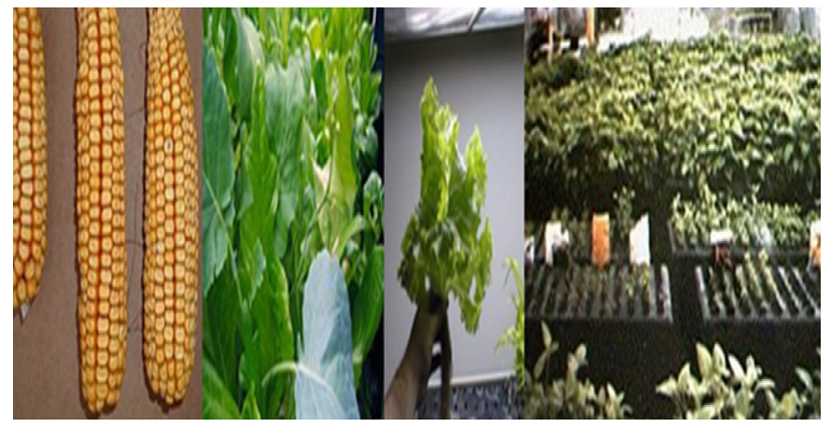

Fig. 13 Aeroponic method of growing plants

teamed up with AgriHouse and BioServe Space Technologies to design an experiment to test a soilless plant-growth system on board the Mir Space Station. NASA was particularly interested in this technology because of its low water requirement. Using this method to grow plants in space would reduce the amount of water that needs to be carried during a flight, which in turn decreases the payload. Aeroponically grown crops also can be a source of oxygen and drinking water for space crew.

Aeroponics systems, which utilize a high-pressure pump to spray nutrients and water onto the roots of a plant, are essential for long-term space missions in the future. Aeroponic growing systems provide clean, efficient, and rapid food production. Crops can be planted and harvested yearround without interruptions, and without contamination from soil or pesticide use. Plants grown in aeroponic systems have also been shown to take in more vitamins and minerals, making the plants healthier and potentially more nutritious. These "space gardens" could provide up to half of the required calories for the astronauts through tomatoes, potatoes and other fruits and vegetables. It can also help to recycle nutrients, provide drinking water and create oxygen in space [35]. According to AgriHouse (product outcome of NASA research program), growers choosing to employ the aeroponics method can reduce water usage by $98 \%$, fertilizer usage by $60 \%$, and pesticide usage by $100 \%$, all while maximizing their crop yields by $45-75 \%$.

\subsubsection{Soil Improvement}

Another possible solution is to improve the required soil portion needed for agriculture. For example, if the greenhouse method is employed, the soil is still needed.

In case the soil nutrients and other conditions are not perfect for plants growth on the deep space destination, the soil portion could be improved. Poor and less-than-ideal soil for planting could benefit from amendments, which improve the nutrient and moisture levels while supplying aeration and structure. Mixing a 2-inch-thick layer of compost into soil is sufficient when that soil is already relatively good, but heavy

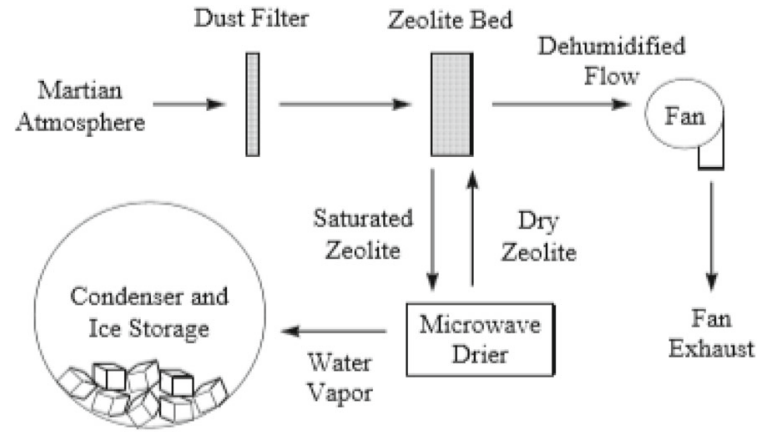

Fig. 14 The WAVAR process

clay soil or sandy soil may require a 4-6-inch thick layer of the amendment to reap its benefits. Compost and commercial fertilizer provide nutrients to soil, but applying them regularly is necessary to maintain the soil's nutrient level. If the soil $\mathrm{pH}$ is not correct, then lime could be added to raise the $\mathrm{pH}$ or sulfur to lower the $\mathrm{pH}$, but additional 6 months will be required before planting, so the amendment has time to alter the soil's chemical makeup [9].

\subsubsection{Solution to Water Use of Plants}

Mars is revealing more and more evidence that it probably once had liquid water on its surface, and 1 day will become a home away from home for humans. One of the major problems to solve is the water that is needed for the growth of the plants, Mars contains approximately $60 \%$ of water, of this, $1 \%$ is in the atmosphere and the other is mostly frozen.

The University of Washington has designed an in situ resource utilization system to provide water to the life support system in the laboratory module of the NASA Mars Reference Mission, a piloted mission to Mars [38]. In this system, the Water Vapor Adsorption Reactor (WAVAR) (see Fig. 14), extracts water vapor from the Martian atmosphere by adsorption in a bed of type $3 \mathrm{~A}$ zeolite molecular sieve. Using ambient winds and fan power to move atmosphere, the WAVAR adsorbs the water vapor until the zeolite $3 \mathrm{~A}$ bed is nearly saturated and then heats the bed within a sealed chamber by microwave radiation to drive off water for collection. The water vapor flows to a condenser where it freezes and is later liquefied for use in the life support system [38].

On the Moon however, scientists have conjectured that water ice could survive in cold, permanently shadowed craters at the Moon's poles. For Venus, because of the average temperature of $467{ }^{\circ} \mathrm{C}$, there will not be any water on it, but could water be in the clouds and atmosphere of Venus as it contains $0.002 \%$ water vapor? 


\subsubsection{Biotechnologically Transformation of Food Plants}

The environment in Mars, Moon and Venus are inhospitable for plants growth, therefore, plants can be made to survive on these selected celestial bodies by genetic transformation to suite these environments. The genetic transformation is usually done through biotechnological means. This involves isolation of desired gene or the gene of interest from the host's genome and inserting it into the genome of the organism required to possess the phenotype. Examples include:

- Adding features from microscopic organisms called extremophiles that live in the most inhospitable environments on earth. The technique includes gene splicing (genetic or DNA alteration) to remove useful genes from extremophiles and adding them to plants.

- Transformation of plants with genes for cold tolerance, e.g., taking useful genes from bacteria that have cold tolerance in arctic ice.

- Transformation of other plants with genes from tomato plants that have ultraviolent resistance that grows high in the Andes mountains.

\subsubsection{Mathematical/Theoretical Model for Plant Growth Simulation on Selected Celestial Bodies Using Data from Microgravity Facilities and Microgravity Simulations Facilities}

Microgravity is an outer space condition of absolute weightlessness. The gravity on the earth is $9.807 \mathrm{~m} / \mathrm{s}^{2}$. Gravity on the Moon is one-sixth of the gravity on Earth (i.e., dividing $9.807 \mathrm{~m} / \mathrm{s}^{2}$ by 6 ) and this corresponds to $1.622 \mathrm{~m} / \mathrm{s}^{2}$. Gravity on the Mars is one-third of the gravity on Earth (i.e., dividing $9.807 \mathrm{~m} / \mathrm{s}^{2}$ by 3 ) and this corresponds to $3.711 \mathrm{~m} / \mathrm{s}^{2}$. Gravity on the Venus is nine-tenth of the gravity on Earth (i.e., dividing $9.807 \mathrm{~m} / \mathrm{s}^{2}$ by $9 / 10$ ) and this corresponds to $8.87 \mathrm{~m} / \mathrm{s}^{2}$. There is no microgravity in the Moon, Mars and Venus; therefore, microgravity experiments will not be applicable to them since there is no microgravity in them, but theoretical models to get the growth rate of plants in relation to the gravity available on these celestial bodies using available data from microgravity facilities and microgravity simulations facilities. This will give an insight to the expected growth rate and yield of plants to be grown on the selected celestial destinations, if they will be able to deliver the required quantity of nutrients to the crew.

Indeed, gravity has shaped the plant and animal world over millions of years, and man spend much of his live resisting it. Gravity has supplied a constant input throughout the evolution of life on Earth, providing a directional cue by which plants organize cells, tissues, and organs; and they elaborate their body plans. The various means by which the force of acceleration due to gravity is perceived, transduced, and transmitted throughout the body of the plant remains an active and important research enterprise, drawing upon the latest tools in cell biology, biochemistry, molecular genetics, signal transduction, and physiology to advance our understanding of this complex response [39, 40]. In addition, the development of an international effort to explore space has provided opportunities to investigate plant growth responses in the microgravity environment of low-Earth orbit aboard Spacelab, Mir, the International Space Station (ISS), US Space Shuttle missions, and various satellite-based lab environments [41-43].

Plants evolved in the presence of gravity and they developed molecular and cellular mechanisms to adjust growth according to physical forces in a $1 \mathrm{~g}$ world. Reduced gravity environments influence the plants physical environment that again affects the physiological transport of water and solutes, and gas exchange between the plant and its surroundings [44]. Through this force of gravity, the growth of plant organs is coordinated, enabling plants to conquer and explore the space below and above the surface of the Earth. Gravity guides the growth direction of germinating seedlings allowing downwards growing primary roots to explore the soil for water and minerals and upwards growing shoots to synthesize sugars by photosynthesis in the light. This directional growth along the gravity vector, known as gravitropism, allows plants to control and adjust the optimal orientation, but the molecular mechanisms and underlying signaling networks are far from being understood [40, 45-50]. It was shown that relocalization of statoliths (starch-filled plastids located in columella cells) and changes in auxin distribution play important roles in gravity signal transduction $[51,52]$.

In the past, many growth chambers for plants (although not regenerative systems) have been designed, produced and then used in Space. Examples of these structures are: AstrocultureTM System (NASA); Plant Growth Unit (NASA), Plant Growth Facility (NASA), Svet (Bulgaria and Russia), Plant Generic BioProcessing Apparatus (NASA), Biomass Production System (NASA), Commercial Plant Biotechnology Facility (NASA), Plant Research Unit (NASA) and the European Modular Cultivation System (ESA). However, access to microgravity, such as provided by the ISS, is rare and costly. Moreover, alternatives to overcome these limitations such as drop towers, suborbital rockets and parabolic flights using airplanes unfortunately allow only short experimental time windows. Ground simulation (bedrest, centrifuge, random positioning machines, magnetic levitation and immersion) are better longer means. Models like the clinostat allow the assessment of microgravity induced deconditioning effects, and reveal gravitational mechanisms in the plant/animal physiological systems, as well as mechanisms involved in adaptation of the plant/animal to microgravity. In particular, they allow researchers to develop and test measures to counter the deleterious effects of weightlessness. Immersion is one 
of these models, because it creates conditions that closely resemble the gravity-free environment.

2-D clinostat appears as an ideal approach to study aspects of gravity perception and signal transduction as it provides the possibility to simulate microgravity on ground and can be used to prepare or to validate microgravity experiments. 2-D clinostats allow rotating objects along a horizontal axis perpendicular to the gravitational vector to generate high quality of reduced gravity conditions [53-55]. Several experiments conducted worldwide using clinoration and involving various model plants have improved the understanding of the mechanisms governing plant response to simulated microgravity [56-65]. Clinostat principles and different available clinostats are discussed in Brungs et al. [66]. Clinostat are therefore available in Earth laboratories. Clinostat is an experimental device used in an Earth laboratory to simulate microgravity or to eliminate the effect of gravity.

Experimental Example An example was done by growing wheat on Clinostat at the Space Agency of Nigeria-National Space Research and Development Agency (NASRDA), Abuja, Nigeria. Wheat (Triticum) is one of the most important food cereal crops having health benefits [67]. The properties that make wheat suitable for this experiment is that the seeds are small, easy to handle and fast-growing with germination time of 2 days. Plants roots are structures specialized for anchorage, storage, absorption and conduction [68]. Plants roots-anatomy is very important for graviresponses and in plant physiology generally. In this particular experiment, the roots of the plants were used for growth rate analysis under $1 \mathrm{~g}$ and simulated microgravity. The $1 \mathrm{~g}$ result serves as control experiment, while the corresponding growth rate of wheat on the Moon, Mars and Venus were extrapolated from the two values of data gotten.

\section{Objectives}

- To understand what the impact of the gravity of Moon, Mars and Venus will have on the growth rate of wheat plant seeds. The idea behind this is to know what their orientation will be on the Moon, Mars and Venus where there is reduced gravity. With clinostat experiments, the importance and impact of gravity can be demonstrated.

- To conduct observational experiments with respect to the differences under microgravity environment and comparing them with those of control experiments under gravity and extrapolating what will be observed on the Moon, Mars and Venus. This was done using the growth rates of wheat determined by their root lengths.

Benefits This scientific research provides insights into Moon, Mars and Venus farming. Understanding how wheat grow on the Moon, Mars and Venus will create a data set of

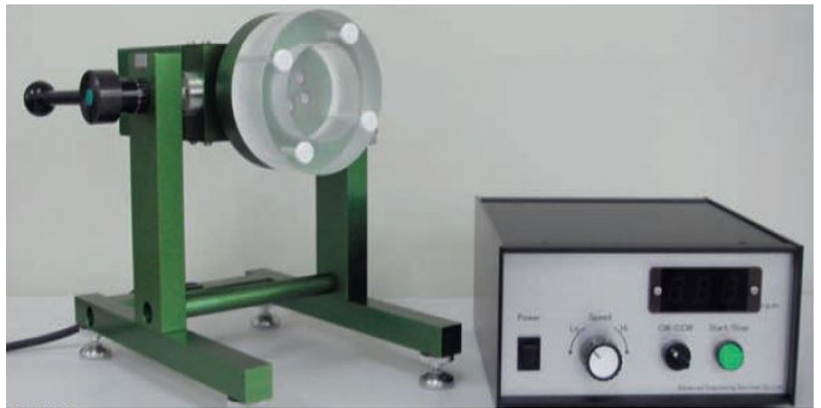

Fig. 15 Uniaxial clinostat and its control box. Rotation position of the clinostat in the picture is horizontal, therefore, having rotational axis angle of $90^{\circ}$

experimental results in various gravity conditions that will contribute to the design of future space experiments and research.

Materials and Methods The seeds of wheat were bought and authenticated to be the actual seeds sought after. The seeds were planted into 2 Petri dishes using plant-substrate called agar, following the standard preparation method in the Teacher's Guide to Plant Experiments by United Nations Office for Outer Space Affairs (UNOOSA) of the Programme on Space Applications [69]. The petri-dishes were then put on petri-dish holders in vertical positions (since gravity acts vertically) and then into a wet chamber. The following conditions were maintained throughout the experiment: humidity between 60 to $100 \%$, temperature of $23^{\circ} \mathrm{C}$ and light of $50 \mathrm{~lx}$.

After 2 days under $1 \mathrm{~g}$, germination of the seeds with short roots (of at least $50 \mathrm{~mm}$ ) were observed. The 2 Petri dishes were then taken and labeled " 1 g-control" and "Clinorotated". The $1 \mathrm{~g}$-control labeled sample was remained in the vertical position and the Clinorotated-sample was then placed at the centre of the clinostat using double-sided tape (see Fig. 15). This means that the 1 g-control sample was still left under $1 \mathrm{~g}$, while the Clinorotated-sample mounted on the clinostat was then under simulated microgravity. The $1 \mathrm{~g}$ control sample served as a control for growth rate analysis for the clinorotated-sample. The clinorotated-sample mounted on the clinostat was under the following conditions: fast rotation-speed of $85 \mathrm{rpm}$, rotational-axis angle of $90^{\circ}$ and rotation-direction was clockwise.

The photos of the 2 petri-dishes were taken every $30 \mathrm{~min}$. The clinorotated-sample was stopped for just some seconds to snap to avoid the effect of gravity. These observations were done for $6 \mathrm{~h}$. Note that the light-conditions, temperature, humidity, rotation-speed, rotation-direction, rotational-axis angle (vertical or horizontal), and time of observation are the experimental variables for Clinostat experiments.

At the end of observations, the root-anatomy of wheat plants seeds were studied using specialized-software called 


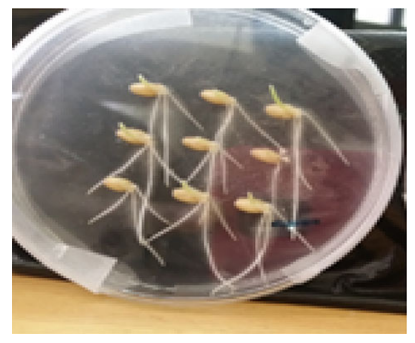

Fig. 16 Photo of the $1 \mathrm{~g}$-control sample of wheat

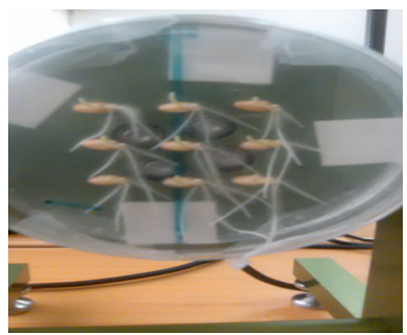

Fig. 17 Photo of the clinorotated sample of wheat

Image $\mathrm{J}$ to analyse the roots lengths from the two sets of pictures taken. The grand average root lengths of all the seeds were calculated per hour to give the growth-rates.

Results The data obtained were the two sets of photos of the roots which show the " 1 g-control" and "Clinorotated" roots (see Figs. 16 and 17). An image-processing application soft-ware called ImageJ was used to analyse these photos.

Growth Rate of the Roots The pictures of the $1 \mathrm{~g}$-control and the clinorotated roots of the wheat were used for this analysis. This was done by measuring the length of the roots, which thereby allowed their growth rate to be determined. It had three roots growing per seed, the longest root was measured. The length of the roots was measured by drawing a line which is exactly $10 \mathrm{~mm}$ long on each petri-dish. This line was used to standardize $10 \mathrm{~mm}$ length on the ImageJ software serving as a fixed length in the photo. After standardization, the length measurement tool was used to measure the length of each of the roots in $\mathrm{mm}$. The clinorotated sample of wheat plant showed increased growth rate per hour than the counterpart $1 \mathrm{~g}$-control sample (as shown in Table 5). Average value of all the length of the nine $1 \mathrm{~g}$-roots for each time points was calculated and then, the grand-average of the lengths were then calculated (as shown in Table 6). This grand-average value was then divided by 6 which is the duration time (in hours) of the time of observation.

Since the plant was examined for $6 \mathrm{~h}$, therefore, the growth rate of the $1 \mathrm{~g}$-control sample is $26.676 / 6=4.446 \mathrm{~mm} / \mathrm{h}$.

Since the plant was examined for $6 \mathrm{~h}$, therefore, the growth rate of the Clinorotated sample is $29.352 / 6=4.892 \mathrm{~mm} / \mathrm{h}$.
Mathematical/Theoretical Model for Simulating Plant Growth on the Moon, Mars and Venus The grand average of the growth rate of the $1 \mathrm{~g}$ control Sample is $26.676 \mathrm{~mm}$

The grand average of the growth rate of the Clinorotated Sample is $29.352 \mathrm{~mm}$

The Moon's gravity is 1/6 of the Earth's gravity, therefore the root length of wheat that will be planted on Moon will be $26.676 / 6=4.446 \mathrm{~mm}$ (as shown in Table 7).

For the simulated microgravity, the Moon's wheat root length will be $29.352 / 6=4.892 \mathrm{~mm}$ (as shown in Table 7).

The average $=\frac{4.446+4.892}{2}=\frac{9.338}{2}=4.669 \mathrm{~mm}$

(as shown in Table 8).

Since the plant was examined for $6 \mathrm{~h}$, therefore, the growth rate will be $4.669 / 6=0.778 \mathrm{~mm} / \mathrm{h}$.

The Mars' gravity is $1 / 3$ of the Earth's gravity, therefore, the root length of wheat that will be planted on Moon will be $26.676 / 3=8.892 \mathrm{~mm}$ (as shown in Table 7).

For the simulated microgravity, the Mars' wheat root length will be $29.352 / 3=9.784 \mathrm{~mm}$ (as shown in Table 7).

The average $=\frac{8.892+9.784}{2}=\frac{18.676}{2}=9.338 \mathrm{~mm}$

(as shown in Table 8).

Since the plant was examined for $6 \mathrm{~h}$, therefore, the growth rate will be $9.338 / 6=1.556 \mathrm{~mm} / \mathrm{h}$.

The Venus' gravity is 9/10 of the Earth's gravity; therefore, the root length of wheat that will be planted on Moon will be $26.676 \times 9 / 10=24.0084 \mathrm{~mm}$ (as shown in Table 7).

For the simulated microgravity, the Venus' wheat root length will be $29.352 \times 9 / 10=26.4168 \mathrm{~mm}$ (as shown in Table 7).

The average $=\frac{24.0084+26.4168}{2}$

$$
\begin{aligned}
& =\frac{50.4252}{2} \\
& =25.213 \mathrm{~mm}
\end{aligned}
$$

(as shown in Table 8).

Since the plant was examined for $6 \mathrm{~h}$, therefore, the growth rate will be $25.213 / 6=4.202 \mathrm{~mm} / \mathrm{h}$.

Observations were made using the photos of growth of wheat under $1 \mathrm{~g}$ and on simulated microgravity using clinostat. The photos of the $1 \mathrm{~g}$-control showed that the roots continuously grew vertically as stimulated by the Earth's gravity. For the clinorotated roots, however, nothing stimulates their growth in any direction. The theoretical/mathematical model has made it very easy to simulate the rate of growth of wheat on the Moon, Mars and Venus and therefore, the length of time that the plants will use to grow till full usage can also be estimated. 


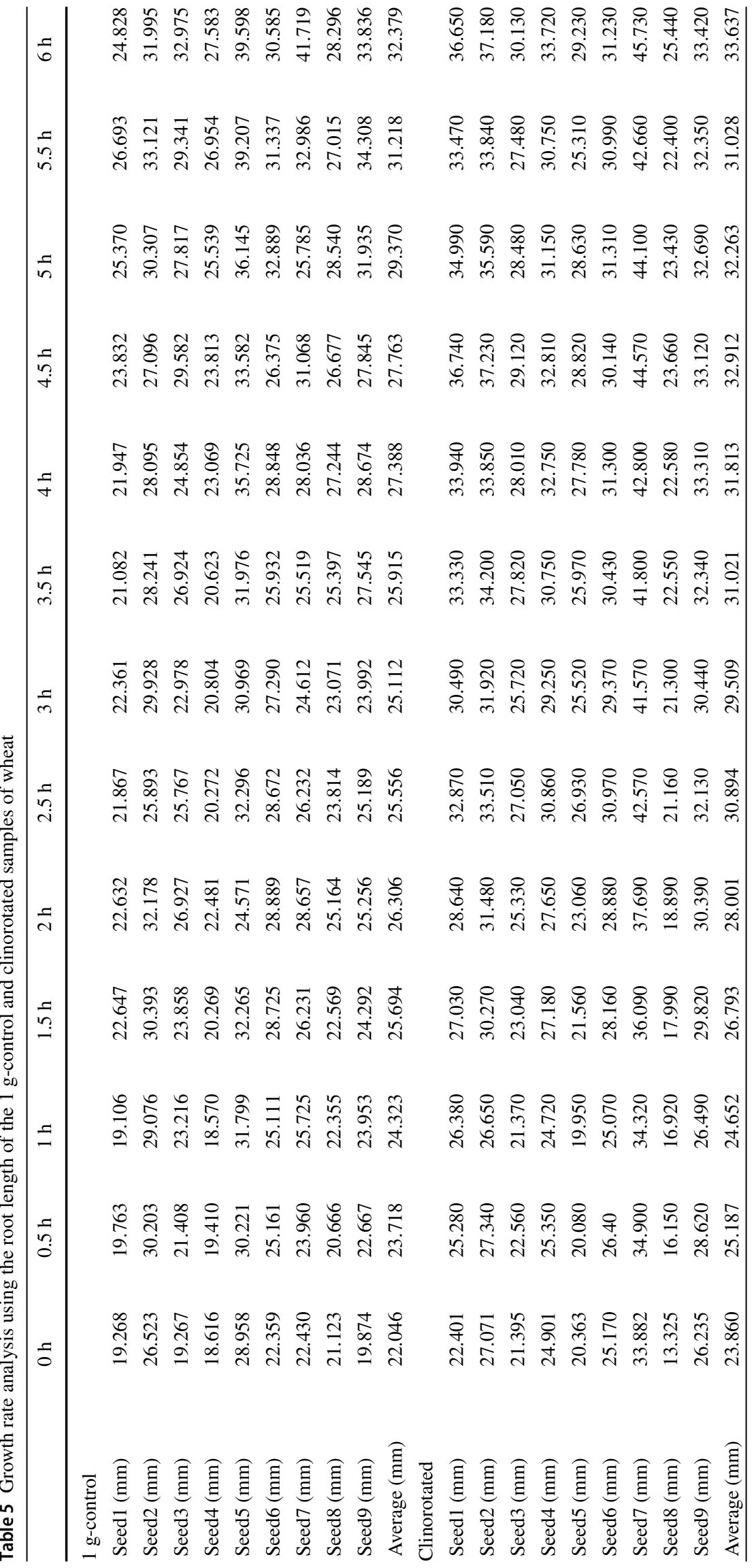


Table 6 Grand Averages of the growth rate analysis of the $1 \mathrm{~g}$-control and clinorotated Samples of wheat

\begin{tabular}{lll}
\hline Time $(\mathrm{h})$ & $1 \mathrm{~g}$-control $(\mathrm{mm})$ & Clinorotated $(\mathrm{mm})$ \\
\hline 0 & 22.046 & 23.860 \\
0.5 & 23.718 & 25.187 \\
1 & 24.323 & 24.652 \\
1.5 & 25.694 & 26.793 \\
2 & 26.306 & 28.001 \\
2.5 & 25.556 & 30.894 \\
3 & 25.112 & 29.509 \\
3.5 & 25.915 & 31.021 \\
4 & 27.388 & 31.813 \\
4.5 & 27.763 & 32.912 \\
5 & 29.370 & 32.263 \\
5.5 & 31.218 & 31.028 \\
6 & 32.379 & 33.637 \\
Average & 26.676 & 29.352 \\
\hline
\end{tabular}

These all add to the analytical knowledge of the effect of various gravity conditions on wheat for future space missions. The extrapolated result, therefore, will give a great idea and result into Moon, Mars and Venus farming for crews' survival (see Fig. 18).

\section{Food Choice Considering Psychosocial and Cultural Factors}

Psychological and social issues will affect space explorers crew due to the isolation, confinement, and long separa- tion from family and friends. Cultural issues, interpersonal stressors, effects of long-term microgravity and radiation, extreme isolation and loneliness, limited social contacts and novelty, lack of support from Earth due to communication delays, family problems at home, gender roles, increased home sicknesses, depression, habitat design, sleep, sexual attraction/tension, etc., are some of the psychosocial issues [70], and food will not be an exception. Over the course of a few decades, psychological research into "analogue sites" here on earth, simulations, and astronauts living and working in orbit has started to show how humans are affected by such environments. In general, findings show the potential for conflict or emotional deterioration during long-term isolated periods, but it may have more to do with people's perceptions of their environment more so than the environment itself. Even still, living in isolated and confined areas can cause stress and problematic behaviours that may interfere with productivity and relationships [71]. Food will also be an important factor. As a result of the crew members from different parts of the world with different cultural backgrounds and food, not eating the desired food may affect the morale of some crew members. Food choice for astronauts affects them psychosocially. They should be allowed to select their menu as long as it constitutes the required nutrients. With the advent of high-tech 3D food printers, freshly prepared food to the crew-member's preferences will be made possible.

\section{Discussion}

Early explorers discovered the importance of nutrition, often at their peril. There is therefore, a need to carefully pre-
Table 7 Converted values for growth rate from $1 \mathrm{~g}$-control and clinorotated samples

\begin{tabular}{|c|c|c|c|c|c|c|}
\hline \multirow[t]{2}{*}{ Time (h) } & \multicolumn{3}{|c|}{$\begin{array}{l}1 \text { g-control values converted } \\
(\mathrm{mm})\end{array}$} & \multicolumn{3}{|c|}{$\begin{array}{l}\text { Clinorotated values converted } \\
(\mathrm{mm})\end{array}$} \\
\hline & Moon & Mars & Venus & Moon & Mars & Venus \\
\hline 03 & 0.674333 & 7.348667 & 19.8414 & 3.976667 & 7.953333 & 21.474 \\
\hline 0.5 & 3.953000 & 7.906000 & 21.3462 & 4.197833 & 8.395667 & 22.6683 \\
\hline 1 & 4.053833 & 8.107667 & 21.8907 & 4.108667 & 8.217333 & 22.1868 \\
\hline 1.5 & 4.282333 & 8.564667 & 23.1246 & 4.465500 & 8.931000 & 24.1137 \\
\hline 2 & 4.384333 & 8.768667 & 23.6754 & 4.666833 & 9.333667 & 25.2009 \\
\hline 2.5 & 4.259333 & 8.518667 & 23.0004 & 5.149000 & 10.29800 & 27.8046 \\
\hline 3 & 4.185333 & 8.370667 & 22.6008 & 4.918167 & 9.836333 & 26.5581 \\
\hline 3.5 & 4.319167 & 8.638333 & 23.3235 & 5.170167 & 10.34033 & 27.9189 \\
\hline 4 & 4.564667 & 9.129333 & 24.6492 & 5.302167 & 10.60433 & 28.6317 \\
\hline 4.5 & 4.627167 & 9.254333 & 24.9867 & 5.485333 & 10.97067 & 29.6208 \\
\hline 5 & 4.895000 & 9.790000 & 26.433 & 5.377167 & 10.75433 & 29.0367 \\
\hline 5.5 & 5.203000 & 10.40600 & 28.0962 & 5.171333 & 10.34267 & 27.9252 \\
\hline 6 & 5.396500 & 10.79300 & 29.1411 & 5.606167 & 11.21233 & 30.2733 \\
\hline Average & 4.446000 & 8.892000 & 24.0084 & 4.892000 & 9.784000 & 26.4168 \\
\hline
\end{tabular}


Table 8 Averages of the extrapolated values for root lengths of wheat to be grown on moon, mars and venus using values generated from earth and microgravity (simulated) as standard

\begin{tabular}{llllll}
\hline Time (h) & Earth & $\begin{array}{l}\text { Simulated } \\
\text { Microgravity } \\
\text { Clinorotated } \\
(\mathrm{mm})\end{array}$ & $\begin{array}{l}\text { Moon } \\
\text { Average value } \\
\text { fmm })\end{array}$ & $\begin{array}{l}\text { Mer the } \\
\text { converted }\end{array}$ & $\begin{array}{l}\text { 1 g-control and } \\
\text { Clinorotated }(\mathrm{mm})\end{array}$ \\
\hline 0 & 22.046 & 23.86 & 3.825500 & 7.651000 & 20.65770 \\
0.5 & 23.718 & 25.187 & 4.075417 & 8.150833 & 22.00725 \\
1 & 24.323 & 24.652 & 4.081250 & 8.162500 & 22.03875 \\
1.5 & 25.694 & 26.793 & 4.373917 & 8.747833 & 23.61915 \\
2 & 26.306 & 28.001 & 4.525583 & 9.051167 & 24.43815 \\
2.5 & 25.556 & 30.894 & 4.704167 & 9.408333 & 25.40250 \\
3 & 25.112 & 29.509 & 4.551750 & 9.103500 & 24.57945 \\
3.5 & 25.915 & 31.021 & 4.744667 & 9.489333 & 25.62120 \\
4 & 27.388 & 31.813 & 4.933417 & 9.866833 & 26.64045 \\
4.5 & 27.763 & 32.912 & 5.056250 & 10.11250 & 27.30375 \\
5 & 29.370 & 32.263 & 5.136083 & 10.27217 & 27.73485 \\
5.5 & 31.218 & 31.028 & 5.187167 & 10.37433 & 28.01070 \\
6 & 32.379 & 33.637 & 5.501333 & 11.00267 & 29.70720 \\
Average & 26.676 & 29.352 & 4.669000 & 9.338000 & 25.21300 \\
\hline
\end{tabular}

Fig. 18 Graph of wheat seeds growth on the earth and in simulated microgravity with the extrapolated growth values in Moon, Mars, and Venus using the root lengths and time after germination

\section{Growth Rate of Wheat Seeds on the Earth and in Simulated Microgravity with the Extrapolated Growth Rate in Moon, Mars and Venus}

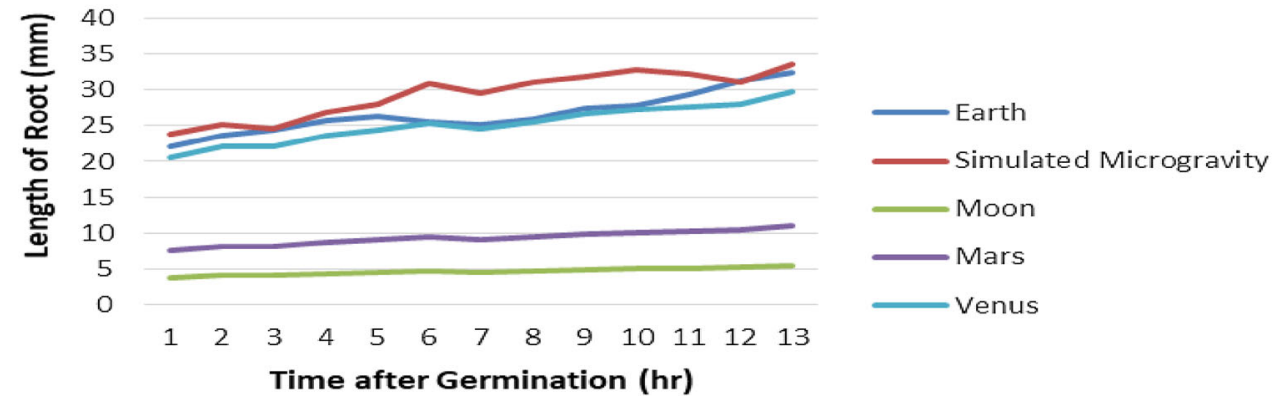

pare ahead on the feeding of crew on the surfaces of Moon, Mars and Venus by growing their crops themselves. Several suggestions and recommendations in this project have being given to make this possible. This include the seeds growth rate extrapolations for Moon, Mars and Venus from microgravity/simulated microgravity platforms. Upon research, viable and desired seeds should be taken along with the crew. If plants can be successfully grown on Moon, Mars and Venus, there is a higher chance of sustaining human life and growth in the future, as well as having the astronauts well nourished.

Advancements in food nutrient to meet the challenges of space have resulted in many commercial products. Very soon much more from space food spin-offs will be seen on the shelves of departmental stores. Therefore, food technology spin-offs from space are beneficial throughout the world. Advancements in food packaging, preservation, preparation and nutrient to meet the challenges of space resulted in many commercial products. Research conducted to determine the impact of spaceflight on human physiology and subsequent nutritional requirements will also have direct and indirect applications in Earth-based nutrition research. Today hydroponics and aeroponics are used in agriculture around the globe [72].

\section{Conclusions}

Various alternatives to feeding crew members on deep space missions to selected celestial destinations of Moon, Mars and Venus were analyzed. It will be too costly to be sending food to mission crews at these destinations; therefore, alternatives of planting by crew to feed themselves are given in this project. The characteristics of the Earth that makes it 
habitable for plants to grow were used to judge if the Moon, Mars and Venus are habitable for plants to grow. This was because growing on other celestials require the same basic ingredients for plants to grow on Earth.

Various hazards to plant as a result of the hostile environment of these celestials were identified, creating a comprehensive list of risks requiring mitigation. These hazards were then evaluated and possible solutions for risk mitigation on plants were proposed based on literature review and experimental research. The results are a list of recommendations that should be considered for feeding the crew on deep manned space missions on the Lunar, Martian and Venus surfaces.

The study found the following researches on Earth as the possible solutions to be able to design how to feed the crew members on the missions at their various selected celestial destinations. Growing seeds on soil simulations (of Moon, Mars and Venus) on the ground and using CubeSats; solutions to plant growth against the atmospheric and radiation challenges (environmental) using greenhouse, aquaponics, hydroponics, aeroponics and soil improvement methods; solution to water use of plants; biotechnologically transformation of food plants to survive on the selected celestial destinations; and extrapolating growth rates of seeds from microgravity/microgravity simulation platforms to develop mathematical/theoretical models for plant growth on the various celestial destinations and to know if the seeds will give the crew members the desired quantity of nutrients; an experimental research example was given for the microgravity/microgravity simulation platforms.

The study found that growing plants on the surface of the Mars, Moon and Venus without any other aid such as greenhouse, soil improvement, etc., is not scientifically possible as a result of their hostile environment. Therefore, the various alternatives already analyzed should be looked into more to serve as possible solutions for feeding the crews. Another key finding of the study is that when astronauts are able to grow and eat the kind of food they want in long term space missions, this reduces the effect of psychosocial of isolation, confinement, and long separation from family and friends on them. The proposed high-tech 3D food printers will also serve as part of the solution to challenges caused by food related psychosocial. Apart from the psychosocial roles of food, the physiological roles of the nutrients in the food cannot also be over-emphasized on crew's health.

In all, some of the possible solutions to growing seeds on the selected celestial destinations are already successfully developed. It is then within our reach to start or to complete the on-going design/research of the other mentioned possible solutions to further clear the path for crewed missions to deep space missions.
Acknowledgements UNOOSA in Vienna, Austria for contributing Clinostat to National Space Research and Development Agency (NASRDA), Obasanjo Space Centre, Abuja, Nigeria.

Open Access This article is distributed under the terms of the Creative Commons Attribution 4.0 International License (http://creativecomm ons.org/licenses/by/4.0/), which permits unrestricted use, distribution, and reproduction in any medium, provided you give appropriate credit to the original author(s) and the source, provide a link to the Creative Commons license, and indicate if changes were made.

\section{References}

1. Huntress W, Stetson D, Farquhar R, Zimmerman J, O'Neil W, Bourke R, Foing B (2006) The next steps in exploring deep space, a cosmic study by the International Academy of Astronautics, 20 Feb 2006, http://www.lpi.usra.edu/lunar/strategies/AdvisoryGrou pReports/iaa_report.pdf. Accessed 21 June 2017)

2. United-Nations (2017) The World Population Prospects: the 2017 Revision, published by the UN Department of Economic and Social Affairs

3. Lupisella ML (2001) Human mars mission contamination issues, science and the human exploration of mars, 11-12 Jan 2001, NASA Goddard Space Flight Center, Greenbelt, MD. LPI Contribution No. 1089. Accessed 15 Nov 12)

4. Taylor Redd N (2018) Red giant stars: facts, definition and the future of the sun: space.com contributor

5. Musk E. If we make it to Mars, we will have answered the question of whether humanity is fated to be a single-planet or multi-planet species. Tesla Founder

6. Oko D (2015) On the long trip to Mars, what will astronauts eat? https://www.houstonchronicle.com/local/gray-matters/artic le/On-the-way-to-Mars-what-will-astronauts-eat-6248511.php. Accessed 15 June 2018)

7. NASA (National Aeronautics and Space Administration) (1999) Space food and nutrition, an educator's guide with activities in science and mathematics

8. Atmosphere of Earth, https://en.wikipedia.org/wiki/Atmosphere_ of_Earth. Accessed 21 June 2017)

9. Harrington J, What are the three important benefits that soil provides? http://homeguides.sfgate.com/three-important-benefits-soi 1-provides-100960.html

10. Michael CH (2006) The surface of Mars, Cambridge planetary science series 6 (Cambridge University Press), ISBN 0-521-87201$4, \mathrm{p} 16$

11. Quizlet, Chapter 12 learning review, what is the difference between soil and regolith, https://quizlet.com/39839469/chapter-12-learnin g-review-flash-cards/

12. MacElroy RD, Kliss M, Straight C (1992) Life support systems for Mars transit, Adv. Space Res 12:159-166. Mohr H, Blue light responses: phenomena and occurrence in plants and microorganisms. Senger $\mathrm{H}$ (ed) CRC Press

13. Kag B (2012) Res Rev J Agric Sci Technol 1(1):26-35

14. Herbert GW (1996) One way to mars-the case for Mars VI Workshop

15. Mackenzie B (1998) One way to Mars-a permanent settlement on the first mission. Presented at the International Space Development Conference

16. Heldmann LJ, Jennifer L et al (2005) Formation of Martian gullies by the action of liquid water flowing under current Martian environmental conditions. J Geophys Res 110(E5):7

17. Kluger J (1992) Mars, in earth's image. Discover Magazine, Retrieved 03 Nov 2009 
18. Sunlight on Mars-Is there enough light on Mars to grow tomatoes? https://www.firsttheseedfoundation.org/resource/tomatosph ere/background/sunlight-mars-enough-light-mars-grow-tomatoe s/

19. https://www.google.com.ng/?gfe_rd=cr\&ei=wTdJWff8F8jO8ged zIuABQ\#q=what+is+the+distance+of +the+Moon+from+the+eart h\&spf $=1498082193155$. Accessed 21 June 2017)

20. https://www.space.com/18145-how-far-is-the-Moon.html. Accessed 21 June 2017)

21. What is the Moon made off, https://www.thoughtco.com/what-isthe-Moon-made-of-604005. Accessed 21 June 2017)

22. Air Pollution on the Moon, http://www.geoffreylandis.com/Moon air.html.Accessed 06 Dec 2016)

23. NASA, Radioactive Moon. Science Beta, 2005

24. Redd NT (2012) Venus' atmosphere: composition, climate and weather

25. Carter J (2018) Should we go to Venus instead of Mars? https:// www.techradar.com/news/should-we-go-to-venus-instead-of-mar $\mathrm{s}$

26. Marín E (2016) Las plantas cultivadas en suelo marciano son perfectamente comestibles. https://es.gizmodo.com/las-plantas-culti vadas-en-suelo-marciano-son-perfectame-1782574207. Accessed 05 May 2018)

27. Wamelink GWW, Frissel JY, Krijnen WHJ, Verwoert MR, Goedhart PW (2014) Can plants grow on mars and the moon: a growth experiment on mars and moon soil simulants. PLoS One 9(8):e103138. https://doi.org/10.1371/journal.pone.0103138

28. International Potato Center (CIP) (2017) Indicators show potatoes can grow on mars. https://cipotato.org/blog/indicators-show-potat oes-can-grow-mars/. Accessed 30 Apr 2018

29. DA Ramírez (2017) International Journal of Astrobiology, Cambridge University, Press Extreme salinity as a challenge to grow potatoes under Mars-like soil conditions: targeting promising genotypes 1 (2017), Page 1 of 7 https://doi.org/10.1017/S1473550417000453.https://www.camb ridge.org/core/services/aop-cambridgecore/content/view/5B9C2 55DC0CC2FA7F0C0849C5FECD0BC/S1473550417000453a.p df/extreme_salinity_as_a_challenge_to_grow_potatoes_under_ marslike_soil_conditions_targeting_promising_genotypes.pdf. Accessed 02 May 2018)

30. De Micco V, Aronne G, Colla G, Fortezza R, De Pascale S (2009) Agro-biology for bioregenerative life support systems in longterm space missions: general constraints and the Italian efforts. J Plant Interactions 4(4):241-252. https://doi.org/10.1080/174291409031 61348

31. Herridge L, Griffin A (2017) How does your space garden grow? https://www.nasa.gov/feature/how-does-your-space-garde n-grow. Accessed 23 June 2018)

32. NASA (National Aeronautics and Space Administration), A Plant Growth Chamber. https://www.nasa.gov/audience/foreducators/pg ig003.html. Accessed 24 June 2018)

33. Griffin A (2017) Cabbage patch: Fifth crop harvested aboard space station. http://www.nasa.gov/feature/cabbage-patch-fifth-crop-har vested-aboard-space-station. Accessed 23 June 2018

34. Schlehahn D, Boudreau A, Barber B, Kowalchuk B, Langman B, Worobec J (2017) Can a greenhouse be established on Mars? Univ Saskatchewan Undergrad Res J 4(1):1-13

35. Alavudeen A (2014) A seminar Report on Space Food TechnoKerala Agricultural University, Post Harvest Technology and Agricultural Processing, Kelappaji College of Agricultural Engineering and Technology, Tuvanur-679573. Malappuram, Kerala

36. Rakocy JE, Bailey SD, Shultz CR, Thoman SE (2013) Update on Tilapia and Vegetable Production in the UVI Aquaponic System (PDF). University of the Virgin Islands Agricultural Experiment Station, Archived (PDF) from the original on 2 March 2013, Retrieved 11 March 2013
37. Plevin P, Foullon P (2016) Autonomous aquaponic system to recreate an ecosystem for Mars settlers, IAC-16, A5, IP,3, x34188, 67th International Astronautical Congress, Guadalajara, Mexico

38. Grover MR (1998) Extraction of atmospheric water on mars in support of the mars, reference mission department of aeronautics and astronautics. University of Washington, Box 352400 Seattle, WA 98195-2400 Mars Society Founding Convention, Boulder, CO. file:///C:/Users/Andrea/Downloads/WAVAR_Paper_Mars_Soc_co nf_1998.pdf. Accessed 05 May 2018)

39. Kiss JZ (2000) Mechanisms of the early phases of plant gravitropism. Crit Rev Plant Sci 19:551-573

40. Bancaflor EB, Masson PH (2003) Plant gravitropism, unraveling the ups and downs of a complex process. Plant Physiol 133:1677-1690

41. Ferl RR, Wheeler HG, Levine AP (2002) Plants in space. Curr Opin Plant Biol 5:258-263

42. Perbal G, Driss-Ecole D (2003) Mechanotransduction in gravisensing cells. Trends Plant Sci 8:498-504

43. Brinckmann E (2005) ESA hardware for plant research on the International Space Station. Adv Space Res 36:1162-1166

44. Porterfield DM (2002) The biophysical limitations in physiological transport and exchange in plants grown in microgravity. J Plant Growth Regul 21:177-190

45. Palme K (2005) Microgravity applications programme. In: ElmanLarsen B (ed) Successful teaming of science and industry, pp 396-403

46. Teale WD, Paponov IA, Palme K (2006) Auxin in action: signaling, transport and the control of plant growth. Nat Rev Mol Cell Biol 7:847-859

47. Hashiguchi Y, Tasaka M, Morita MT (2013) Mechanism of higher plant gravity sensing. Am J Bot 100:91-100

48. Cui D, Zhao J, Jing Y, Fan M, Liu J, Wang Z, Xin W, Hu Y (2013) The Arabidopsis IDD14, IDD15, and IDD16 cooperatively regulate lateral organ morphogenesis and gravitropism by promoting auxin biosynthesis and transport. PLoS Genet 9:e1003759

49. Sang D, Chen D, Liu G, Liang Y, Huang L, Meng X, Chu J, Sun X, Dong G, Yuan Y, Qian Q, Li J, Wang Y (2014) Strigolactones regulate rice tiller angle by attenuating shoot gravitropism through inhibiting auxin biosynthesis. Proc Natl Acad Sci USA 111:11199-112204

50. Sack FD, Suyemoto MM, Leopold AC (1985) Amyloplast sedimentation kinetics in gravistimulated maize roots. Planta 165:295-300

51. Singh M, Gupta A, Laxmi A (2014) Glucose and phytohormone interplay in controlling root directional growth in Arabidopsis. Plant Signal Behav 9:e29219

52. Leitz G, Kang BH, Schoenwaelder MEA, Staehelin LA (2009) Statolith sedimentation kinetics and force transduction to the cortical endoplasmic reticulum in gravity-sensing Arabidopsis columella cells. Plant Cell 21:843-860

53. Hemmersbach R, Von der Wiesche M, Seibt D (2006) Groundbased experimental platforms in gravitational biology and human physiology. Signal Transduct 6:381-387

54. Thiel CS, Paulsen K, Bradacs G, Lust K, Tauber S, Dumrese C, Hilliger A, Schoppmann K, Biskup J, Golz N, Sang C, Ziegler U, Grote KH, Zipp F, Zhuang F, Engelmann F, Hemmersbach R, Cogoli A, Ullrich O (2012) Rapid alterations of cell cycle control proteins in human $\mathrm{T}$ lymphocytes in microgravity. Cell Commun Signal 10:1

55. Herranz R, Anken R, Boonstra J, Braun M, Christianen PCM, de Geest M, Hauslage J, Hilbig R, Hill JA, Lebert M, Medina J, Vagt N, Ullrich O, vanLoon JWA, Hemmersbach R (2013) Ground-based facilities for simulation of microgravity, including terminology and organism-specific recommendations for their use. Astrobiology 13:1-17 
56. Gallegos GL, Hilaire EM, Peterson BV, Brown CS, Guikema JA (1995) Effects of microgravity and clinorotation on stress ethylene production in two starchless mutants of Arabidopsis thaliana. $\mathrm{J}$ Gravit Physiol 2:153-154

57. Kordyum EL, Danevich LA (1995) Calcium balance changes in tip growing plant cells under clinorotation. J Gravit Physiol 2:147-148

58. Kordyum E, Adamchuk N (1997) Clinorotation affects the state of photosynthetic membranes in Arabidopsis thaliana (L.) Heynh. J Gravit Physiol 4:77-78

59. Aarrouf J, Darbelley N, Demandre C, Razafindramboa N, Perbal G (1999) Effect of horizontal clinorotation on the root system development and on lipid breakdown in rapeseed (Brassica napus) seedlings. Plant Cell Physiol 40:396-405

60. Adamchuk NI, Fomishina RN, Mikhaylenko NF, Zolotareva EK (1999) Photosynthetic apparatus of pea leaves under clinorotation conditions. J Gravit Physiol 6:143-144

61. Syvash OO, Adamchuk NI, Dovbysh EP, Zolotareva EK (2008) Effect of clinorotation on Auxin as a model for the integration of hormonal signal processing and transduction. Mol Plant 1:229-237

62. Shevchenko GV, Kordyum EL (2005) Organization of cytoskeleton during differentiation of gravisensitive root sites under clinorotation. Adv Space Res 35:289-295

63. Sobol MA, Gonz'alez-Camacho F, Kordyum EL, Medina FJ (2007) Changes in the two-dimensional proteome of the soluble fraction of nuclear proteins from Lepidium sativum root meristematic cells grown under clinorotation. J Gravit Physiol 14:109-110
64. Soh H, Auh C, Soh WY, Han K, Kim D, Lee S, Rhee Y (2011) Gene expression changes in Arabidopsis is seedlings during short-to long term exposure to 3-D clinorotation. Planta 234:255-270

65. Brykov V, Kordyum E (2015) Clinorotation impacts root apex respiration and the ultrostructure of mitochondria. Cell Biol Int 39:475-483

66. Brungs S, Egli M, Wuest SL, Christianen PCM, Van Loon J, Ngo AJ, Hemmersbach R (2015) Ground-based facilities to simulate microgravity. Microgravity Sci, Technol

67. Health benefits of wheat. https://www.organicfacts.net/health-ben efits/cereal/wheat.html (accessed 07.09.16)

68. Root System Anatomy and Morphology, https://masters.agron.ias tate.edu/classes/533/lesson03/3.2.html. Accessed 14 Jan 2017

69. United Nations (2013) Teacher's guide to plant experiments in microgravity, human space technology initiative. United Nations Programme on Space Applications, New York

70. Kanas N, The New Martians, a scientific novel (2014) ISBN: 9783-319-00974-2. http://www.springer.com/978-3-319-00974-2

71. Slobodian R (2012) Psychosocial challenges of living in space: isolation and culture. York University, Toronto

72. Hoehn A (1998) Root wetting experiments aboard NASA's KC-135 microgravity simulator. BioServe Space Technologies, Boulder 